\title{
ANIMALES METÁLICOS: LOS AROS PREHISPÁNICOS DEL NORTE SEMIÁRIDO DE CHILE COMO REPRESENTACIONES ZOOMORFAS
}

\author{
METALLIC ANIMALS: PREHISPANIC EARRINGS OF THE SEMIARID NORTH \\ OF CHILE AS ZOOMORPHIC REPRESENTATIONS
}

Elvira latorrea, María Teresa Plazab \& Patricio lópez ${ }^{c}$

En este artículo se exponen los resultados del análisis de patrones visuales efectuado en 112 aros metálicos prehispánicos del norte semiárido de Chile. Estos demuestran la presencia de cuatro elementos de diseño mínimo organizados según pautas determinadas generando un número limitado de combinaciones. Cuatro de estas combinaciones podrían leerse como representaciones zoomorfas, a partir de lo cual se crearía una nueva clasificación de acuerdo con los patrones de organización relevados. Al observar la distribución geográfica y cronológica de estos aros, se detectan algunas tendencias que podrán ser discutidas a la luz de nuevos hallazgos.

Palabras clave: norte semiárido, prehispánico, metales, aros, representaciones zoomorfas.

This article presents the results of a visual pattern analysis conducted on 112 pre-Hispanic metal earrings from the semiarid north of Chile. Four minimal elements of design were identified, organized according to a set of predetermined rules, resulting in a limited number of combinations. Four of those combinations could be read as zoomorphic representations, and so a new classification is proposed, based on the organizational patterns identified. Through observations of the geographic and chronological distribution of the earrings, some trends were identified that could be discussed in light of new findings.

Keywords: semi-arid north, pre-Hispanic, metal, earrings, zoomorphic representations.

\section{INTRODUCCIÓN}

Los aros metálicos han sido a menudo mencionados como parte del repertorio de ornamentos utilizados por las poblaciones prehispánicas del norte semiárido de Chile (NSA) (Cornely 1956, Castillo 1989, Niemeyer et al. 1998, Latorre 2009). En el transcurso de la última década, nuevas investigaciones evidencian que se trata de una de las categorías artefactuales más recurrentes y variadas en esta área geográfica y cultural (Latorre \& López 2011). Además, son formas inexistentes o escasamente representadas en regiones vecinas, en contraste con las restantes categorías artefactuales del repertorio de las poblaciones alfareras locales más comunes en el centro sur andino (Latorre 2009, Latorre \& López 2011, Corral 2012, Gutiérrez 2012).

Estudios previos han propuesto una tipología para su clasificación, junto a esbozos interpretativos acerca de su función en la sociedad diaguita (Latorre 2009, Latorre \& López 2011), y los análisis macroscópicos han permitido formular hipótesis sobre las técnicas de manufactura y los metales usados (Latorre 2009, Latorre

A Elvira Latorre Blanco, Investigadora independiente. Av. Grecia 980, Depto. 10, Ñuñoa, Santiago de Chile. E-mail: elviralatorreb@gmail

B María Teresa Plaza Calonge, ucL Institute of Archaeology, 31-34 Gordon Square, Londres WC1H oPy, UK. E-mail: maria.plaza.12@ucl.ac.uk

c Patricio López Mendoza, Museo de Historia Natural y Cultural del Desierto de Atacama, Calama, Chile. E-mail: patriciolopezmend@gmail.com 
\& López 2011, Corral 2012). Sin embargo, pocas piezas disponen de análisis técnicos que determinen con certeza estos y otros aspectos productivos, lo cual es una carencia importante para la investigación del trabajo en metales en el NSA, que se ha basado principalmente en piezas de colecciones, en parte obtenidas de la excavación en contextos funerarios. Esto conlleva un desconocimiento parcial de los sistemas de producción minero-metalúrgicos implementados por estas poblaciones y un desafío para nuevas investigaciones. Dado que los objetos metálicos son el producto final de procesos tecnológicos complejos que involucran distintas etapas articuladas en un sistema de producción, cuya organización está determinada por un contexto sociocultural específico (Lechtman 1979, González 2004), las investigaciones recientes se enfocan en aspectos productivos y tecnológicos. Muchos de estos objetos fueron fabricados como ornamentos destinados a comunicar un mensaje codificado, el que se expresa tanto a través de la tecnología que les da origen como por aspectos visuales asociados a las propiedades inherentes del metal -brillo, color y sonido-, y por la iconografía que se representa.

En el caso de los aros metálicos, con escasas excepciones, se había considerado que su morfología no tenía referentes externos (Latorre 2009). Sin embargo, en el presente trabajo proponemos que gran parte de estos aros corresponden a representaciones zoomorfas, sustentándonos en un análisis que distingue los elementos mínimos de diseño que los componen y los patrones recurrentes que los organizan. A partir de los resultados se sugiere una nueva clasificación, así como examinar sus distribuciones geográficas y cronológicas. Con esto se quiere abrir el camino para un enfoque complementario sobre el trabajo en metales, que, por un lado, observe las piezas terminadas como elementos que están siendo usados y que contribuyen activamente en la construcción de relaciones sociales, y por otro, como elementos identitarios y como objetos que reflejan parte de su mundo natural.

\section{ANTECEDENTES}

Los primeros objetos metálicos registrados en el NSA aparecen en el Período Alfarero Temprano (РAT), en poblaciones denominadas tradicionalmente como complejo cultural El Molle (ca. 0 a 800 DC) (Niemeyer et al. 1989). Cabe aclarar que se usarán a continuación las unidades cronológicas y culturales típicamente definidas para la zona, aun cuando nuevas investigaciones dan cuenta de diferencias, continuidades y coexistencias que proponen un panorama social mucho más complejo (Troncoso \& Pavlovic 2013; Troncoso et al. 2016a, 2016b).

Los metales tempranos se manifiestan en pequeños ornamentos laminares, fabricados en cobre, probablemente sin alear, con escasos ejemplares de oro y plata junto a piezas únicas en aleaciones de cobre/estaño y cobre/ arsénico/níquel (López et al. 2017). No hay evidencias de contextos productivos que permitan determinar una producción local o si se manejaba la metalurgia extractiva. Sin embargo, la presencia de algunas piezas metalúrgicas para sitios PAT de Chile central (Latorre 2006) podría apuntar a que las poblaciones contemporáneas del NSA compartían estos conocimientos, además de recibir objetos cuyas aleaciones revelan manufactura foránea e intercambios a larga distancia (López et al. 2017). Solo se registra un aro adscrito a este período, proveniente del sitio Los Mellizos, en Illapel, asociado a fechas en torno al $1000 \mathrm{DC}$, consideradas tardías para el período (Troncoso et al. 2012).

En contextos del Período Medio (PM), en el que se ubica el complejo cultural Las Ánimas (ca. 800-1200 DC), se amplía la variedad de artefactos fabricados en metal, incluyendo la mayoría de las piezas que tienen continuidad hasta el Período Tardío (PT). La manufactura de piezas laminares se complementa ahora con objetos fabricados mediante el vaciado en moldes, alcanzando tamaños y complejidad mayores a los del PAT. Se utiliza el cobre sin alear, así como la aleación de cobre/estaño y la plata. Las evidencias de contextos productivos son escasas, aunque moldes metalúrgicos de La Puerta A (Niemeyer et al. 1998) y gotas de fundición de Plaza La Serena (Latorre 2011) serían muestras de una producción local y del manejo de tecnologías de metal fundido, así como algunas piezas de aleación de cobre/estaño y otras de morfología diagnóstica denotan la llegada de objetos foráneos (Niemeyer et al. 1998, Corral 2012). En este estadio, además, los aros se vuelven una pieza recurrente en el registro, y sus hallazgos se concentran en los sitios de Plaza Coquimbo, Plaza La Serena y La Puerta A (Castillo 1989; Niemeyer et al. 1991, 1998; Latorre 2011; Corral 2009, 2012).

Del Período Intermedio Tardío (Ріт) hay escasa información, observándose una disminución en la cantidad de objetos provenientes de contextos funerarios (Latorre 2009), aunque moldes metalúrgicos del sitio San 
Julián mostrarían la continuidad del manejo de metal fundido a nivel local (Guajardo 2011). Además, no se han distinguido diferencias significativas en las tecnologías de manufactura ni en la variedad de categorías presentes entre las piezas del complejo Ánimas y los metales diaguitas preincaicos (Latorre 2009). En este período, el único reporte de aros que cuenta con información contextual corresponde a dos piezas procedentes de Punta Teatinos (Montané 1960). La incorporación del semiárido al Tawantinsuyu conlleva un aumento de los objetos metálicos presentes y la introducción de nuevas formas al repertorio existente, como los tumis y los tupus. Asimismo, se encuentran mayores evidencias de contextos productivos que incluyen refractarios, escorias y desechos de manufactura metálica, lo que sería producto de estrategias incaicas para potenciar la producción local de metales, generando piezas que serían entregadas a una elite en contextos de reciprocidad (Latorre 2009). Los aros proliferan para este período tanto en cantidad como en variedad, siguiendo la tendencia general de los objetos metálicos, aunque su hallazgo nuevamente tiende a concentrarse en sitios específicos (Latorre 2009).

La mayor parte de los aros del NSA provendría de ambientes funerarios, donde fueron depositados como ajuar (ver Latorre 2009 y bibliografía citada). Sin embargo, muchos contextos carecen de información o están escasamente documentados, de manera que los análisis bioantropológicos disponibles son pocos, aunque los existentes señalan una asociación, al parecer exclusiva, con individuos adultos de sexo femenino (Latorre 2009). Lamentablemente, tampoco hay evidencias claras de marcos productivos, pese a lo cual los antecedentes revisados direccionan la discusión desde el supuesto de que estas piezas son de producción local. La distribución de estos ornamentos en momentos prehispánicos se centra en el NSA y la Araucanía; sin embargo, también están presentes, aunque en menor cantidad, en la zona central de Chile desde el РАт (Campbell \& Latorre 2003), con un ligero aumento hacia el PT, lo que se ha atribuido a la influencia diaguita (Plaza 2010). En la Araucanía la evidencia más temprana son cinco aros rescatados en Labranza, sitio adscrito al complejo Pitrén fechado en $1160 \pm 40$ AP (Mera et al. 2015).

Posteriormente, los aros serían el elemento más común del repertorio metálico del complejo El Vergel (1000-1550 DC). Se ha propuesto que estas piezas serían un marcador de identidad común, especialmente el tipo cuadrangular con muesca, tratándose de la única forma que tiene una continuidad hasta tiempos históricos, al ser el antecesor de los aros mapuches, los que, tal como los aros del NSA, se asocian exclusivamente a mujeres (Campbell 2004, 2015). Respecto de su distribución en otras áreas, cabe destacar que no están presentes en el repertorio de los principales desarrollos prehispánicos del Norte Grande, mientras que, para el NOA, aunque existe registro de algunas piezas para contextos formativos, no son considerados una forma local (Berón \& González 2006, Rodríguez \& Goretti 2006).

\section{MATERIAL, METODOLOGÍA Y CONCEPTOS}

Para la muestra se seleccionaron aros metálicos procedentes del área comprendida entre la cuenca de Copiapó ( $\left.26^{\circ} 38^{\prime} \mathrm{S}\right)$ y la del Choapa $\left(31^{\circ} 10^{\prime} \mathrm{S}\right)$. Todos ellos están adscritos a distintos momentos de la secuencia alfarera del NSA (1 AC-1536 DC), conservan su cuerpo completo o casi completo y cuentan al menos con un registro visual o descripciones detalladas (ver sitios de procedencia en fig. 1). Un total de 112 piezas cumplieron con estos requisitos, cuya procedencia se resume en la tabla 1 .

Los aros son ornamentos de gran impacto visual. Están fabricados para ser portados y por tanto mostrados, de manera que pueden considerarse como agentes relevantes en la creación y mantención de identidades, y en la construcción de relaciones sociales. Dichos roles deben su efectividad, en parte, a la tecnología usada, pero también a aspectos sensoperceptivos, especialmente visuales, posibles de asociar con procesos semióticos que contribuyen al proceso cultural y contingente, otorgando diversos significados a los objetos (Dobres \& Hoffman 1994; Gell 1992, 1998; Gosden 2001, 2005; Nielsen 2007).

Considerando lo anterior, en el presente trabajo se conciben los aros como signos visuales activos dentro de un sistema de comunicación y, a la vez, como representaciones iconográficas, en el sentido de que muestran una relación formal con un referente externo (Magariños de Morentín 2001). Análisis semióticos orientados a representaciones zoomorfas, específicamente camélidos (ver Balesta 2015, Zaburlín 2016), se apoyan en el análisis del signo visual, reconociendo marcas (sensu Magariños de Morentín 2001) que corresponden a segmentos anatómicos que constituyen las unidades mínimas que se articulan para configurar un atractor, una imagen 


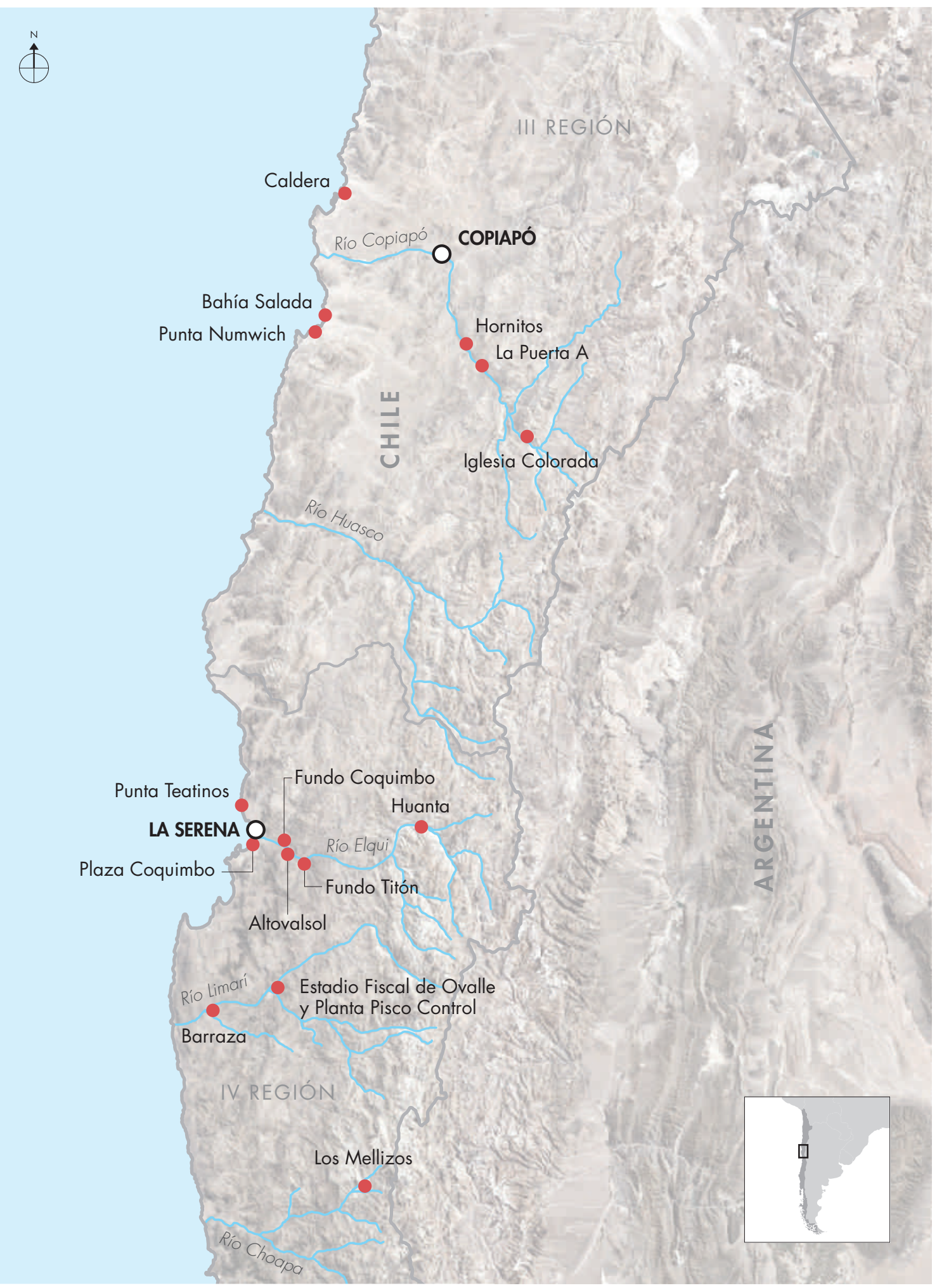

Figura 1. Ubicación de los sitios mencionados en el texto. Figure 1. Map showing location of the sites mentioned in the text. 
Tabla 1. Cantidades de aros por sitio o localidad de procedencia y lugar de depósito o proyecto desde donde fueron recuperados. Table 1. Number of earrings found at each site/locality and context/project associated with the find.

\begin{tabular}{|c|c|c|}
\hline PROCEDENCIA & SITIO/LOCALIDAD & $\mathrm{N}^{\circ}$ \\
\hline \multirow{6}{*}{ Museo Arqueológico La Serena } & Altovalsol & 1 \\
\hline & Barraza & 1 \\
\hline & Fundo Titón & 2 \\
\hline & NSA indeterminado (Colección Schwen) & 3 \\
\hline & Huanta & 1 \\
\hline & Plaza Coquimbo & 16 \\
\hline \multirow{2}{*}{ Museo del Limarí } & Estadio Fiscal de Ovalle (EFo) & 12 \\
\hline & Planta Pisco Control (PPC) & 13 \\
\hline \multirow{2}{*}{ Museo Regional de Atacama } & Costa Copiapó & 2 \\
\hline & La Puerta A & 5 \\
\hline Museo Nacional de Historia Natural & Caldera (Colección Lodwig) & 16 \\
\hline Museo Chileno de Arte Precolombino ${ }^{1}$ & NSA indeterminado (Colección Durruty) & 20 \\
\hline FONDECYT 1080360 & Los Mellizos & 1 \\
\hline EIA Plaza La Serena & Plaza de Armas La Serena & 4 \\
\hline EIA Proyecto Caserones & Copiapó & 2 \\
\hline \multirow{6}{*}{ Bibliografía } & Bahía Salada & 1 \\
\hline & Hornitos & 3 \\
\hline & Iglesia Colorada & 2 \\
\hline & Punta Numwich (sIC, Punta Numwick) & 1 \\
\hline & Punta Teatinos & 2 \\
\hline & Fundo Coquimbo & 4 \\
\hline \multicolumn{2}{|c|}{ TOTAL } & 112 \\
\hline
\end{tabular}

mental que correspondería a un determinado referente. Dobrez y Dobrez (2014) también ponen énfasis en la importancia de la organización de los elementos, en cuanto impulsa el proceso de reconocimiento de una determinada figura como representación zoomorfa. Desde esta mirada, nuestro análisis buscó en primer lugar estas marcas, a las que nos referiremos como elementos mínimos, definidos como figuras geométricas simples que rompen la continuidad del contorno y que en sí mismas no gatillan un reconocimiento. Estudios anteriores muestran que los aros del NSA están construidos de una sola pieza, sin uniones aparentes, que consta de un cuerpo bidimensional del cual surge un arco de forma lineal con un trazado circular u ovalado 
y un extremo libre (Latorre 2009), morfología común a todos los ejemplares. Un primer paso fue determinar el repertorio de formas pertenecientes a cada una de dichas categorías, así como sus frecuencias dentro del grupo. Al mismo tiempo, se delimitó el emplazamiento de cada una de ellas, observando y cuantificando recurrencias, para luego especificar las distintas combinaciones de elementos mínimos y sus frecuencias.

\section{RESULTADOS}

Al descomponer cada aro en sus elementos mínimos se distinguió la presencia recurrente de los siguientes elementos: espirales bidimensionales formadas por una prolongación del cuerpo (o arco) curvada sobre sí misma, cuyo sentido de giro puede ser hacia la derecha (dextrógiro) (fig. 2a) o hacia la izquierda (levógiro) (fig. $2 \mathrm{~b}$ ); apéndices rectangulares con un remate abultado que pueden tender a cónicos (fig. 2c); muescas cuyo contorno puede variar entre triangular y semicircular (fig. 2d); una prolongación semilunar, triangular o cilíndrica añadida que marca la continuación del arco (fig. 2e), y elementos gráficos ubicados sobre el cuerpo o el apéndice cuadrangular (fig. 2f). A excepción de un caso único, donde el cuerpo fue curvado formando un tubo, siempre está presente al menos uno de estos elementos.

El elemento más recurrente es la espiral levógira, registrándose 74 ejemplares $(66,1 \%)$ que portan entre una y siete por pieza, siendo los más frecuentes aquellos con una espiral única, 29,5\% $(n=33)$. Las espirales dextrógiras se encuentran en 11 piezas $(9,8 \%)$, siempre de manera individual. El elemento que les sigue es el apéndice rectangular, presente en un $58 \%(\mathrm{n}=65)$ del conjunto, observándose que un $56,3 \%(\mathrm{n}=63)$ porta un único apéndice, mientras que un $1,8 \%(\mathrm{n}=2)$ presenta dos. Por su parte, la prolongación del arco sólo incluye las alternativas de presencia, con un $44,4 \%(n=36)$ y ausencia en un $55,6 \%(n=45)$.

Los aros que portan muescas representan un $48,2 \%(n=39)$, en cantidades que pueden variar entre una y cuatro por pieza, ubicándose en los lados inferior o superior del cuerpo, individuales o en pares. Por último, un 22,2\% $(n=18)$ porta elementos gráficos en el cuerpo o el apéndice cuadrangular, mayormente grabados lineales con escasos ejemplares repujados. Las configuraciones adoptadas son principalmente en zigzag, aunque también se distinguen campos con líneas oblicuas paralelas, chevrones y rombos concéntricos. Cabe mencionar además que ocho piezas muestran cuentas líticas engarzadas en su arco.

Estos elementos se organizan según un número limitado de patrones, constituyendo seis grandes grupos, pudiendo clasificarse un $97,3 \%(n=109)$ de lo analizado. El patrón más simple contiene un único elemento mínimo conformando el cuerpo, que en un $26,8 \%(n=30)$ es la espiral levógira formada por la prolongación del arco, y en un ejemplar único es un tubo constituido por el cuerpo plegado. El restante $72,3 \%$ $(n=81)$ corresponde a aros compuestos, en los que se distingue un núcleo central, que en la mayoría de los casos puede enmarcarse en una forma de cuatro lados, en torno a la cual se posicionan los elementos mínimos. Entre estos aros compuestos se observa que el vértice superior izquierdo siempre porta algún elemento, en su mayor parte un apéndice cuadrangular, en menor medida espirales dextrógiras y en solo cinco casos espirales levógiras. El vértice inferior izquierdo puede tener una espiral levógira, no llevar ninguna modificación, o bien, en un caso único, mostrar un apéndice cuadrangular, mientras que el vértice inferior derecho puede presentar una espiral levógira, un apéndice aguzado o quedar sin modificación. Las muescas se ubican siempre en los lados superior o inferior. En la figura 3 se muestran ejemplos de la organización de estos elementos en cada uno de los seis grupos definidos.

Para los aros compuestos, la manera en que se organizan los elementos mínimos en torno al cuerpo puede interpretarse en un $65,2 \%(n=73)$ de los casos obedeciendo a la organización de una representación zoomorfa bidimensional de perfil, en cuyo vértice superior izquierdo se ubica un apéndice cuadrangular o una espiral dextrógira, en tanto que en el lado inferior los vértices son ocupados por protuberancias marcadas por muescas o espirales. Dentro del conjunto analizado destaca una pieza (fig. 4) que presenta los mismos elementos mínimos, pero con el añadido de dos elementos gráficos o "marcas" que, junto a una ligera modificación en el perfil del apéndice cuadrangular, entregan información redundante para reconocer este aro como un zoomorfo, es decir, los pequeños abultamientos ubicados en la sección superior del apéndice cuadrangular pueden ser leídos como "ojos".

A partir de la organización observada para los elementos mínimos, y su lectura basada en esta pieza, proponemos que pueden diferenciarse seis grupos 
a

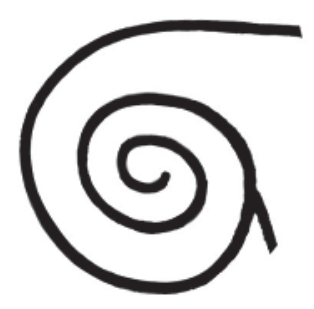

$d$

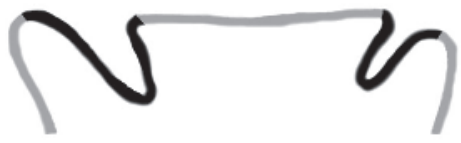

b

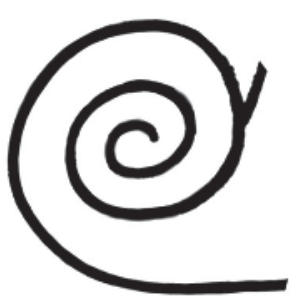

e

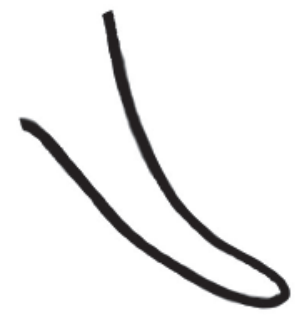

C

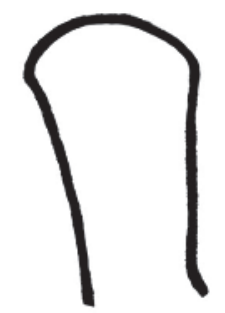

f

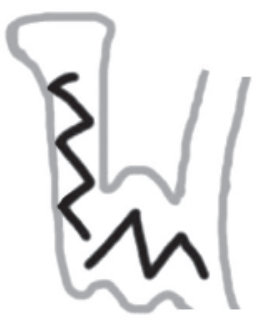

Figura 2. Elementos visuales mínimos presentes en un aro: a) espiral dextrógira; b) espiral levógira; c) apéndice rectangular; d) muescas; e) prolongación semilunar; f) elementos gráficos. Figure 2. Minimal visual elements present in the earrings: $\boldsymbol{a}$ ) dextrorotary spiral; $\boldsymbol{b}$ ) levorotary spiral; c) rectangular appendage; $d$ ) notches; $e$ ) semi-lunate extension; f) graphic elements.

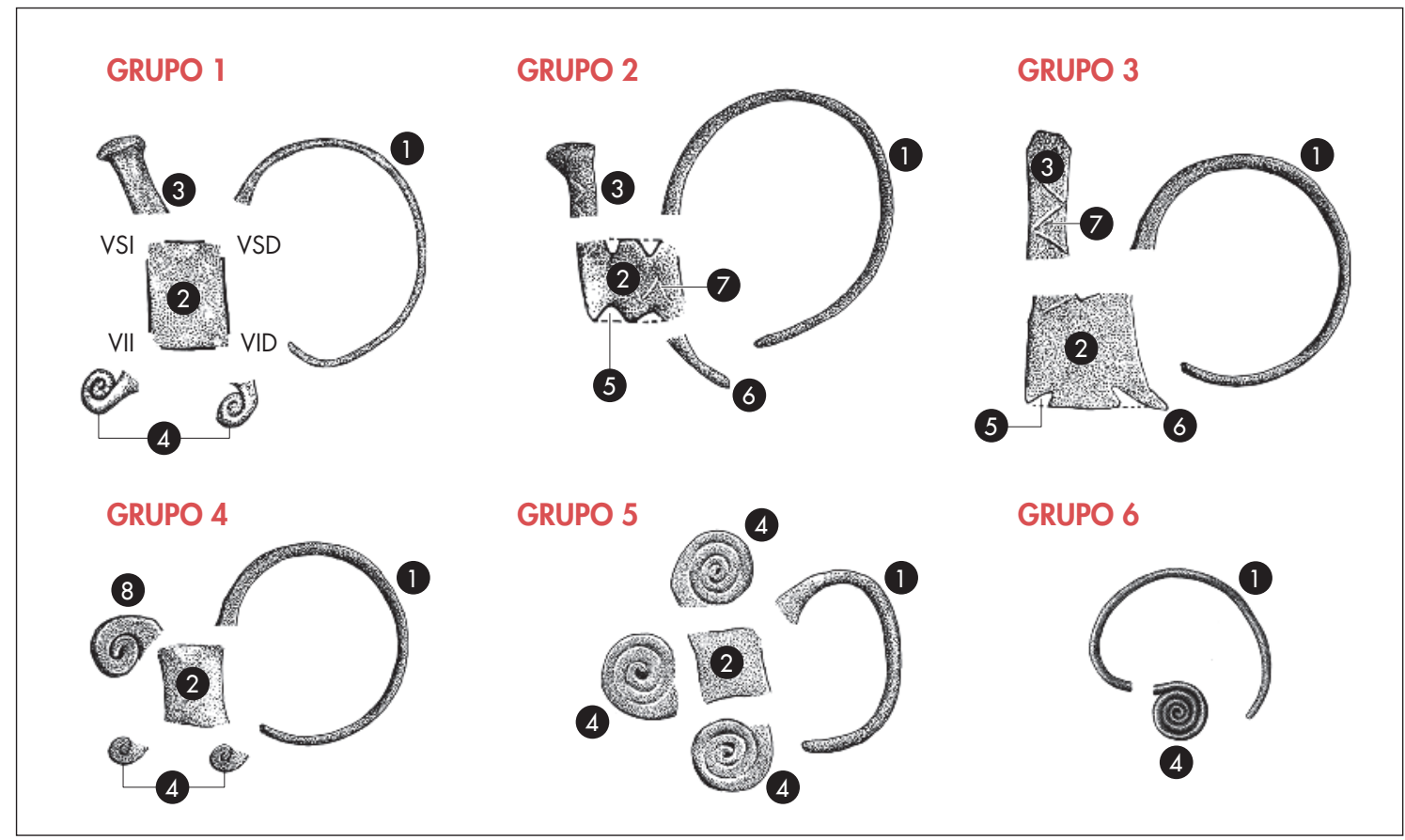

Figura 3. Ejemplos de organización de los elementos mínimos por cada grupo. Leyenda: vsı: vértice superior izquierdo; vsD: vértice superior derecho; viI: vértice inferior izquierdo; viD: vértice inferior derecho. 1) arco, 2) cuerpo, 3) apéndice cuadrangular, 4) espiral levógira, 5) muescas, 6) prolongación del arco, 7) elementos gráficos, 8) espiral dextrógira. Figure 3. Examples of minimal element organization for each group. Legend: VSI: Upper left axis; VSD: Upper right axis; VII: lower left axis; VID: lower right axis. 1) arc, 2) body, 3) quadrangular appendage, 4) levorotary spiral, 5) notches, 6) arc extension, 7) graphic elements, 8) dextrorotary spiral. 
principales, cuatro de los cuales corresponderían a representaciones zoomorfas, mientras que los restantes presentan una organización cuya lectura podría remitir tanto a zoomorfos como a otros referentes. En la tabla 2 se muestran las frecuencias para cada combinación de elementos mínimos, grupo y subgrupo, y a continuación la descripción de cada uno.

El más numeroso es el grupo Zoomorfo 1, con un $25 \%(n=28)$. Se caracteriza por mostrar un apéndice cuadrangular que puede ser largo o corto, acompañado de dos espirales levógiras en los vértices restantes. Tienen cuerpos que pueden ser cuadrados o rectangulares, en su mayoría sin muescas, aunque algunos ejemplares tienen uno o dos pares de ellas. Asimismo, pueden portar grabados ya sea en zigzag horizontal único o doble en el centro del cuerpo, en zigzag vertical en el apéndice cuadrangular o una combinación de ambos. Aquí se identifican dos subgrupos, el primero, que hemos denominado Zoomorfo 1a (fig. 5), presenta cuellos largos, ligeramente inclinados hacia adelante junto a un cuerpo rectangular que tiende a vertical y remata en dos extremidades en espiral. El segundo, Zoomorfo $1 b$ (fig. 6), tiene cuellos cortos acompañados de cuerpos pequeños y cuadrados, además de las dos extremidades en espiral. $\mathrm{El}$ aro figurativo (figs. 4 y 6a) puede clasificarse en este subgrupo, aunque cabe señalar que fue denominado "ornitomorfo" a causa de su hocico aguzado asimilable al pico de un ave (Latorre et al. 2007).

El grupo Zoomorfo 2 está constituido por 19 ejemplares (17\%) que portan un apéndice cónico, en la mayoría de los casos con un remate marcado. No presentan modificaciones en el vértice inferior izquierdo y muestran un apéndice aguzado en el vértice inferior derecho. Su cuerpo puede enmarcarse en un rectángulo apaisado, donde dos pares de muescas definen una forma central romboide, a excepción de una pieza que carece de muescas inferiores. Algunos aros tienen grabados en zigzag horizontal único en el centro del cuerpo, y en zigzag vertical en el apéndice cuadrangular o en ambos (fig. 7).

El grupo Zoomorfo 3, que suma 15 ejemplares $(13,4 \%)$, presenta un apéndice rectangular alargado y plano, no muestra modificación en su vértice inferior izquierdo, mientras que en su vértice inferior derecho incluye una prolongación plana del arco. En su lado superior pueden tener una muesca oblicua poco marcada o ninguna, y en su lado inferior siempre tienen al menos una muesca, que puede ser un ángulo agudo

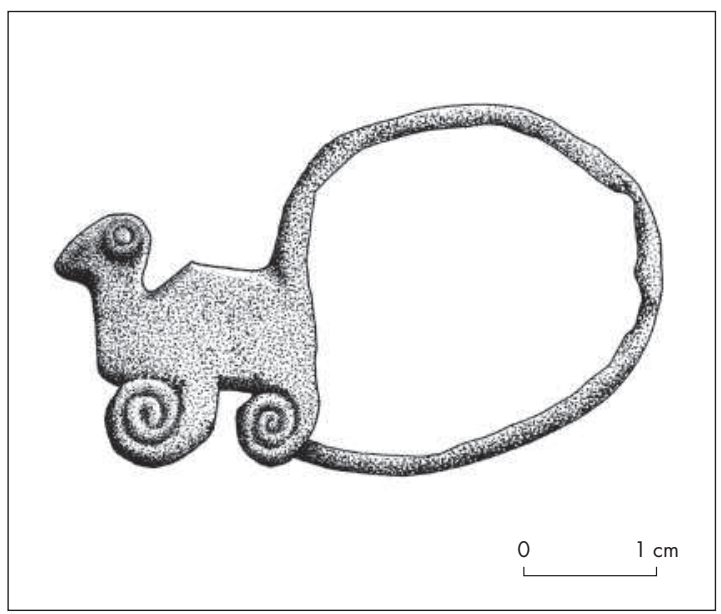

Figura 4. Aro zoomorfo proveniente de Caldera. Su asignación es posiblemente PT, y fue fabricado en cobre o aleación base cobre (dibujo: Elvira Latorre). Figure 4. Zoomorphic earring from Caldera. Possibly assigned to $P T$ and made of copper or copper alloy (drawing: Elvira Latorre).

único, dos ángulos agudos convergentes o un ángulo obtuso redondeado. Pueden portar grabados en zigzag horizontal en el centro del cuerpo o en campos de líneas paralelas perimetrales. Dentro de este grupo es posible distinguir tres subgrupos: los Zoomorfo $3 a$ (fig. 8), que presentan un cuello largo que en algunos casos se inclina hacia el arco junto a un cuerpo de gran tamaño que carece de extremidades, pero en cuyo lado inferior dos muescas convergentes definen tres salientes: dos laterales estrechos y uno central en abanico. Un segundo subgrupo se denomina Zoomorfo $3 b$ (figs. 9a, 9b, 9c y 9d), al portar un cuello largo, junto a un cuerpo donde una gran muesca inferior define dos extremidades protuberantes. El último subgrupo, que se denominó Zoomorfo $3 c$ (figs. 9e y 9f), tiene el mismo cuello largo, pero una muesca oblicua única en su lado inferior.

El grupo Zoomorfo 4, que reúne un 9,8\% ( $\mathrm{N}=11)$, se caracteriza por la presencia de una espiral dextrógira en el vértice superior izquierdo, acompañada por dos espirales levógiras en los vértices restantes. En algunos casos la espiral dextrógira es de mayor tamaño que las restantes. Sus cuerpos tienden a ser rectangulares y no presentan muescas. Pueden tener repujados que ocupan todo el cuerpo en chevrón horizontal o como rombos concéntricos. Aquí se segregan dos subgrupos: Zoomorfo $4 a$ (figs. 10a y 10b), que corresponde a representaciones que se caracterizan por tener una gran espiral dextrógira a manera de cabeza, acompañada 
Tabla 2. Grupos y subgrupos de aros según combinaciones de elementos mínimos. Table 2. Earring groups and subgroups according to combination of minimal elements.

\begin{tabular}{|c|c|c|c|c|c|c|c|c|}
\hline GRUPO & SUBGRUPO & VÉRTICE SI & VÉRTICE II & VÉRTICE ID & MUESCA SUPERIOR & MUESCA INFERIOR & $\mathrm{N}^{\circ}$ & $\%$ \\
\hline \multirow{7}{*}{$\begin{array}{l}\text { Zoomorfo 1 } \\
\text { (Grupo 1) }\end{array}$} & \multirow{3}{*}{ 1a } & & \multirow{3}{*}{ @ } & \multirow{2}{*}{ @ } & & & 13 & 11,6 \\
\hline & & & & & & $\sim$ & 3 & 2,7 \\
\hline & & & & & & & 1 & 0,9 \\
\hline & \multirow{4}{*}{$1 b$} & & \multirow{2}{*}{ @ } & \multirow{2}{*}{ @ } & & & 8 & 7,1 \\
\hline & & & & & & & 1 & 0,9 \\
\hline & & & @ & & & & 1 & 0,9 \\
\hline & & & & & & & 1 & 0,9 \\
\hline \multicolumn{2}{|c|}{ Zoomorfo 2 (Grupo 2) } & & & & $\sim$ & $\sim$ & 19 & 17 \\
\hline \multirow{5}{*}{$\begin{array}{c}\text { Zoomorfo } 3 \\
\text { (Grupo 3) }\end{array}$} & \multirow{2}{*}{$3 a$} & & & & & $\ln$ & 7 & 6,3 \\
\hline & & & & & & UN & 2 & 1,8 \\
\hline & $3 b$ & & & & & & 4 & 3,6 \\
\hline & \multirow{2}{*}{$3 c$} & & & & & & 1 & 0,9 \\
\hline & & & & & & & 1 & 0,9 \\
\hline \multirow{4}{*}{$\begin{array}{c}\text { Zoomorfo } 4 \\
\text { (Grupo 4) }\end{array}$} & $4 \mathrm{a}$ & (2) & @2 & @ & & & 4 & 3,6 \\
\hline & \multirow{3}{*}{$4 \mathrm{~b}$} & \multirow{3}{*}{ (2) } & \multirow{2}{*}{ @ } & (c) & & & 4 & 3,6 \\
\hline & & & & @ @ & & & 2 & 1,8 \\
\hline & & & & & & & 1 & 0,9 \\
\hline \multirow{2}{*}{\multicolumn{2}{|c|}{$\begin{array}{l}\text { Espirales unidireccionales } \\
\qquad(\text { Grupo 5) }\end{array}$}} & @ & @ & @2 & & & 5 & 4,5 \\
\hline & & \multicolumn{5}{|c|}{ @ @ @ @ @ } & 1 & 0,9 \\
\hline \multicolumn{2}{|c|}{ Espiral única (Grupo 6) } & \multicolumn{5}{|c|}{ @ } & 30 & 26,8 \\
\hline \multirow{2}{*}{\multicolumn{2}{|c|}{$\begin{array}{l}\text { Posible zoomorfo } \\
\text { (Piezas únicas) }\end{array}$}} & 8 & & & & & 1 & 0,9 \\
\hline & & R & & & & & 1 & 0,9 \\
\hline \multicolumn{2}{|c|}{ Tubo (Pieza única) } & \multicolumn{5}{|c|}{ 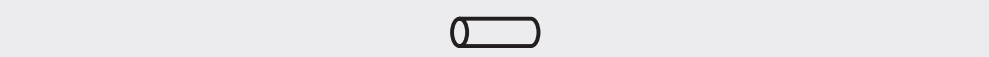 } & 1 & 0,9 \\
\hline \multicolumn{7}{|c|}{ TOTAL } & 112 & 100 \\
\hline
\end{tabular}




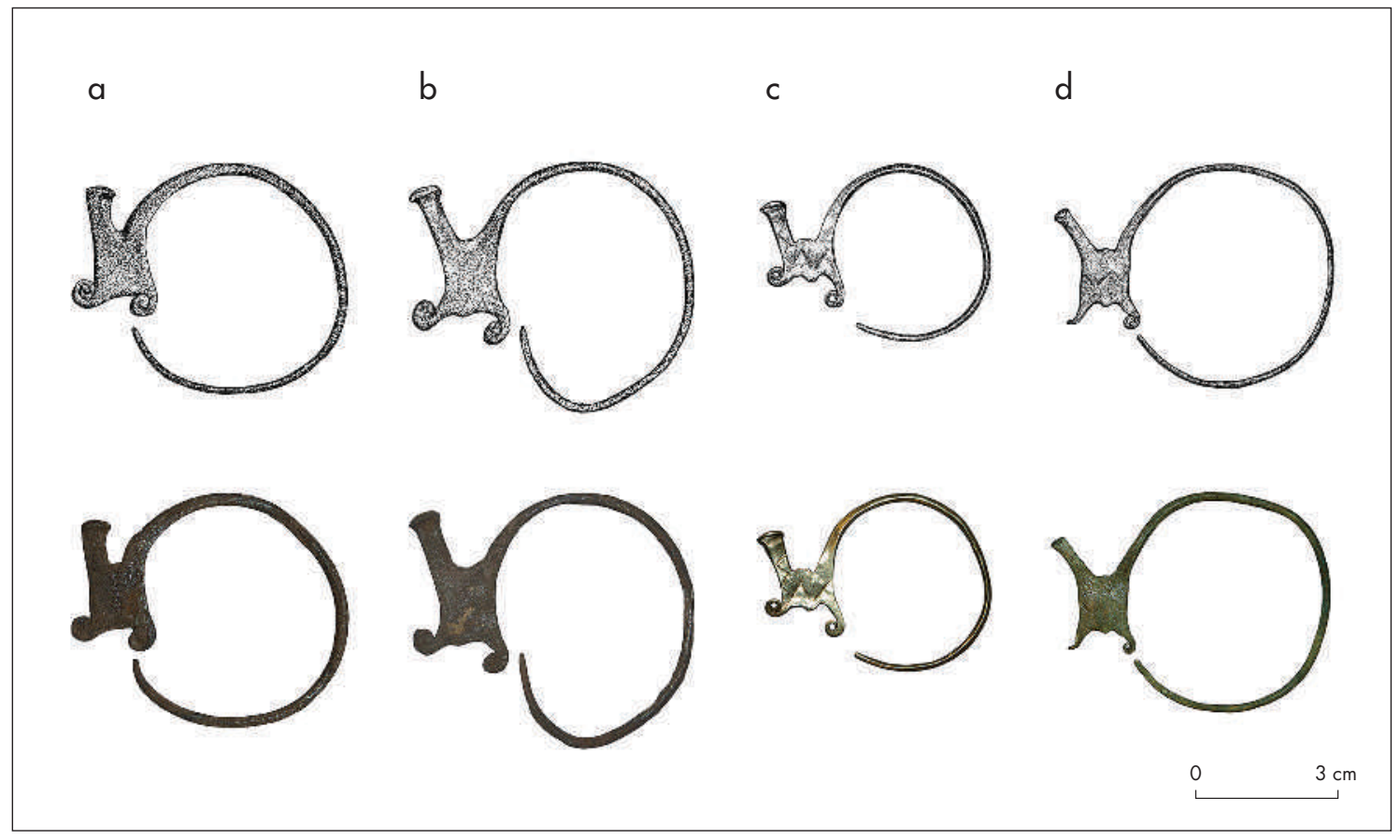

Figura 5. a-d) Aros del tipo Zoomorfo 1a de la colección Durr uty, y de procedencia y cronología indeterminada (dibujos y fotografías: Elvira Latorre). Figure 5. a-d) Earrings from zoomorphic subgroup 1a from the Durruty collection; provenance and chronology indeterminate (drawings and photos: Elvira Latorre).

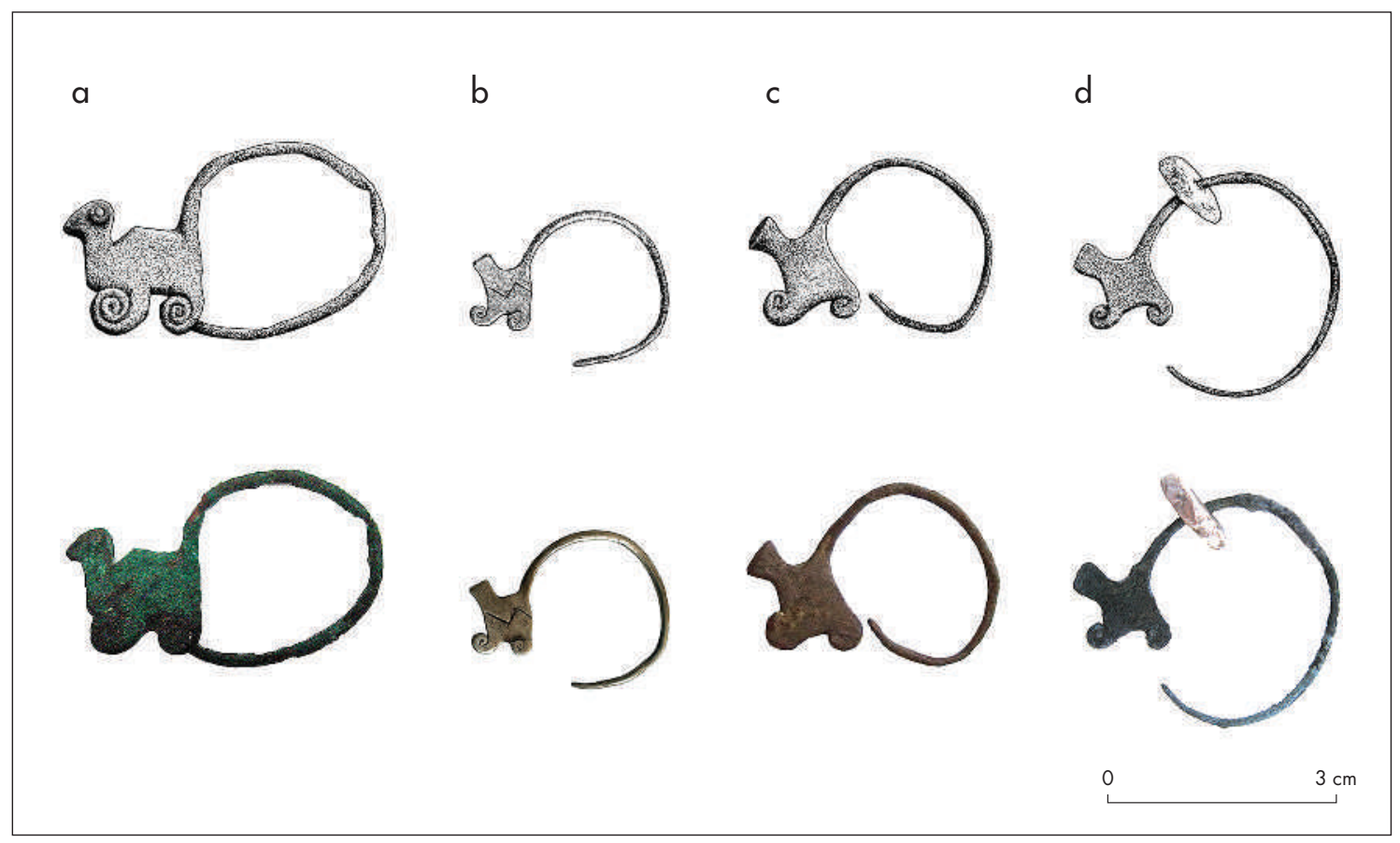

Figura 6. Aros del tipo Zoomorfo 1b. Procedencia: a) Caldera; b) Altovalsol; c) Planta Pisco Control; d) Efo (Dibujos y fotografías: Elvira Latorre). Figure 6. Earrings from zoomorphic group 1b. Provenance a) Caldera; $b$ ) Altovalsol; c) Planta Pisco Control; d) EFo. (drawings and photos: Elvira Latorre). 


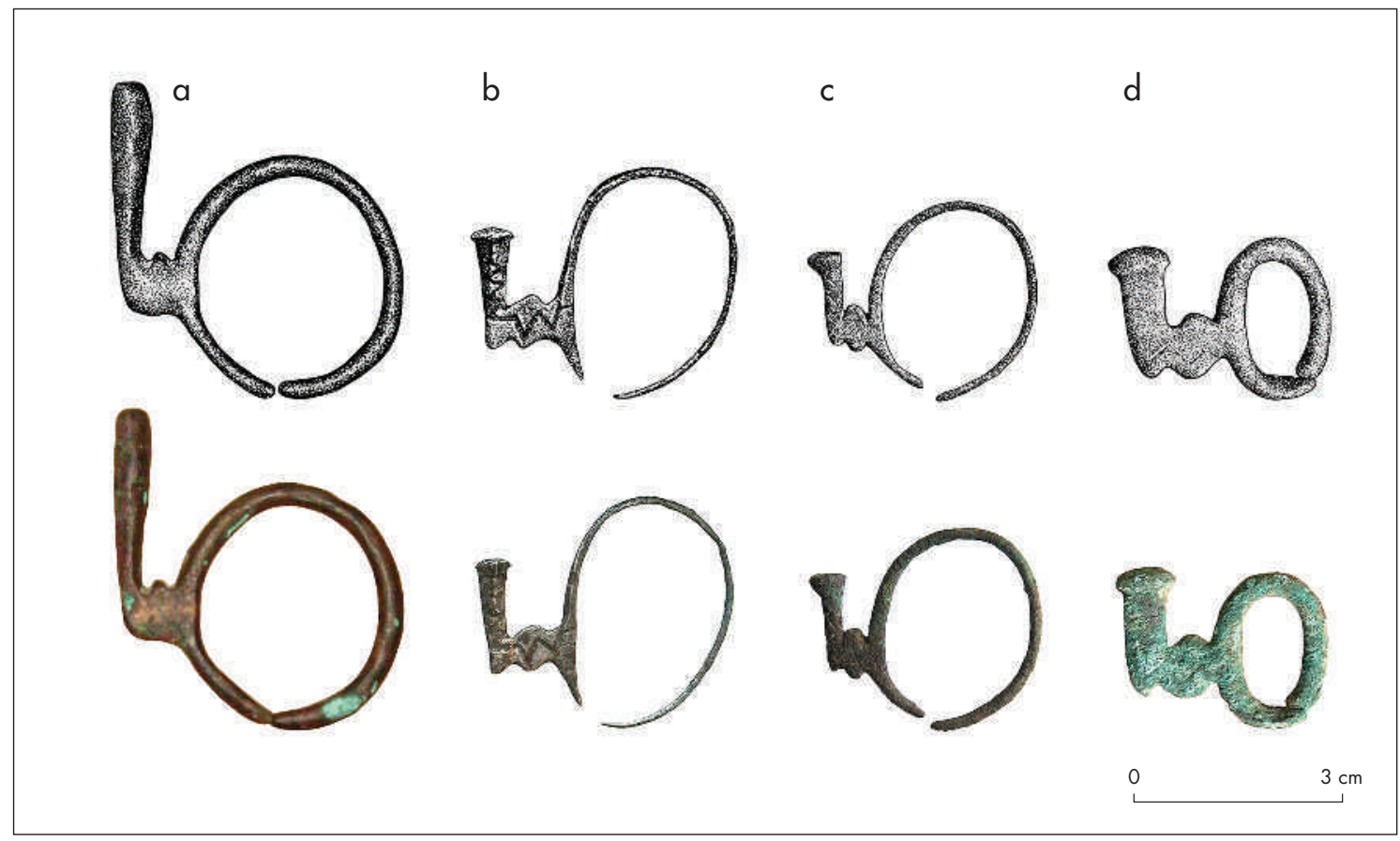

Figura 7. Aros del grupo Zoomorfo 2. Procedencia: a) La Puerta A; b) Barraza; c) Caldera; d) indeterminado (fotografía a: María Ignacia Corral; dibujos y fotografías b-d: Elvira Latorre). Figure 7. Earrings from zoomorphic group 2. Provenance: $\boldsymbol{a}$ ) La Puerta A; b) Barraza; c) Caldera; d) Indeterminate (photo a: María Ignacia Corral; drawings and photos b-d: Elvira Latorre).

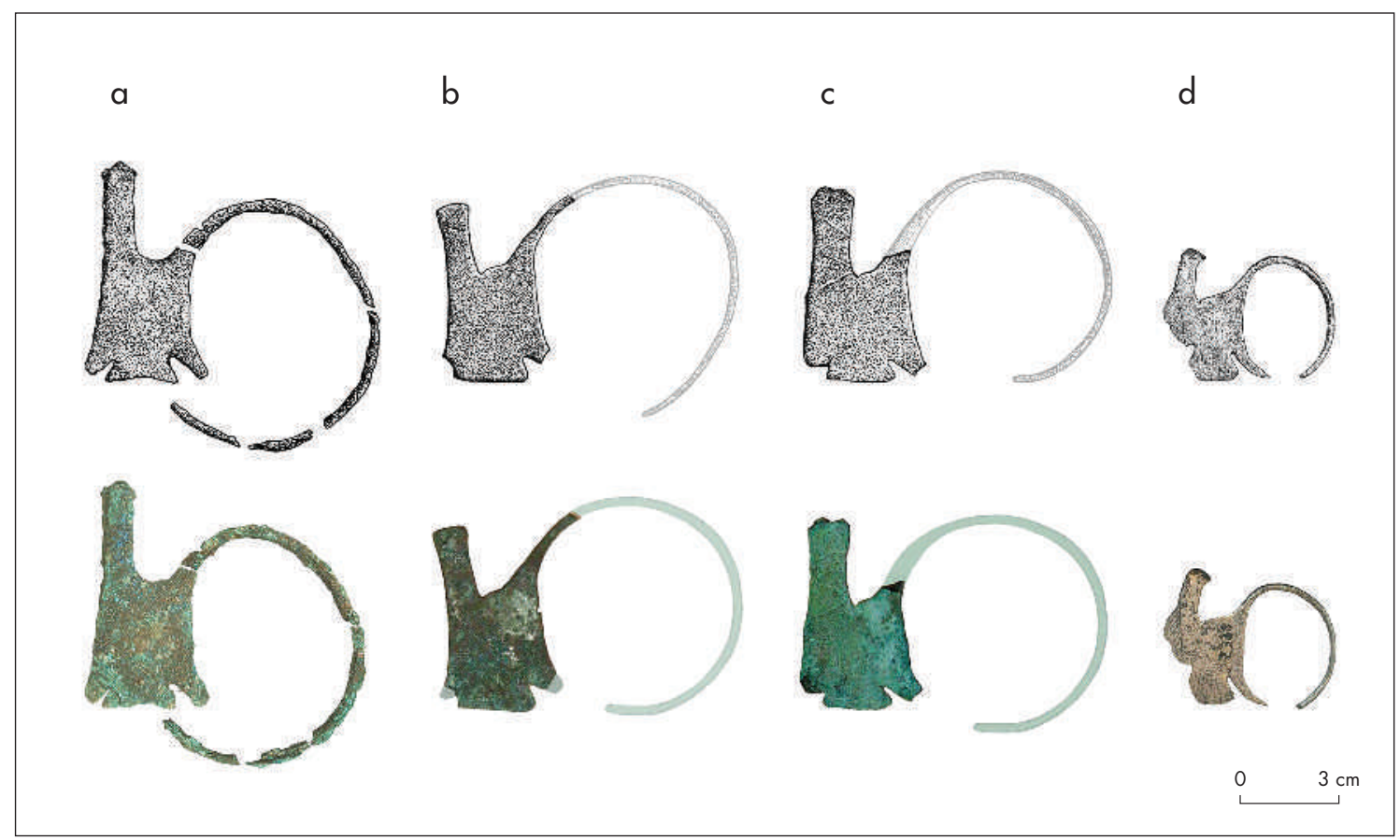

Figura 8. Aros del subgrupo Zoomorfo 3a. Procedencia a) Plaza La Serena; b-c) Plaza Coquimbo; d) Huanta (fotografías a) y d) y dibujos: Elvira Latorre; fotografías b) y c): María Ignacia Corral). Figure 8. Earrings from zoomorphic subgroup 3a. Provenance: a) Plaza La Serena; $\boldsymbol{b}$-c) Plaza Coquimbo; d) Huanta (photos a) and d) and drawings: Elvira Latorre; photos b) and c): María Ignacia Corral). 


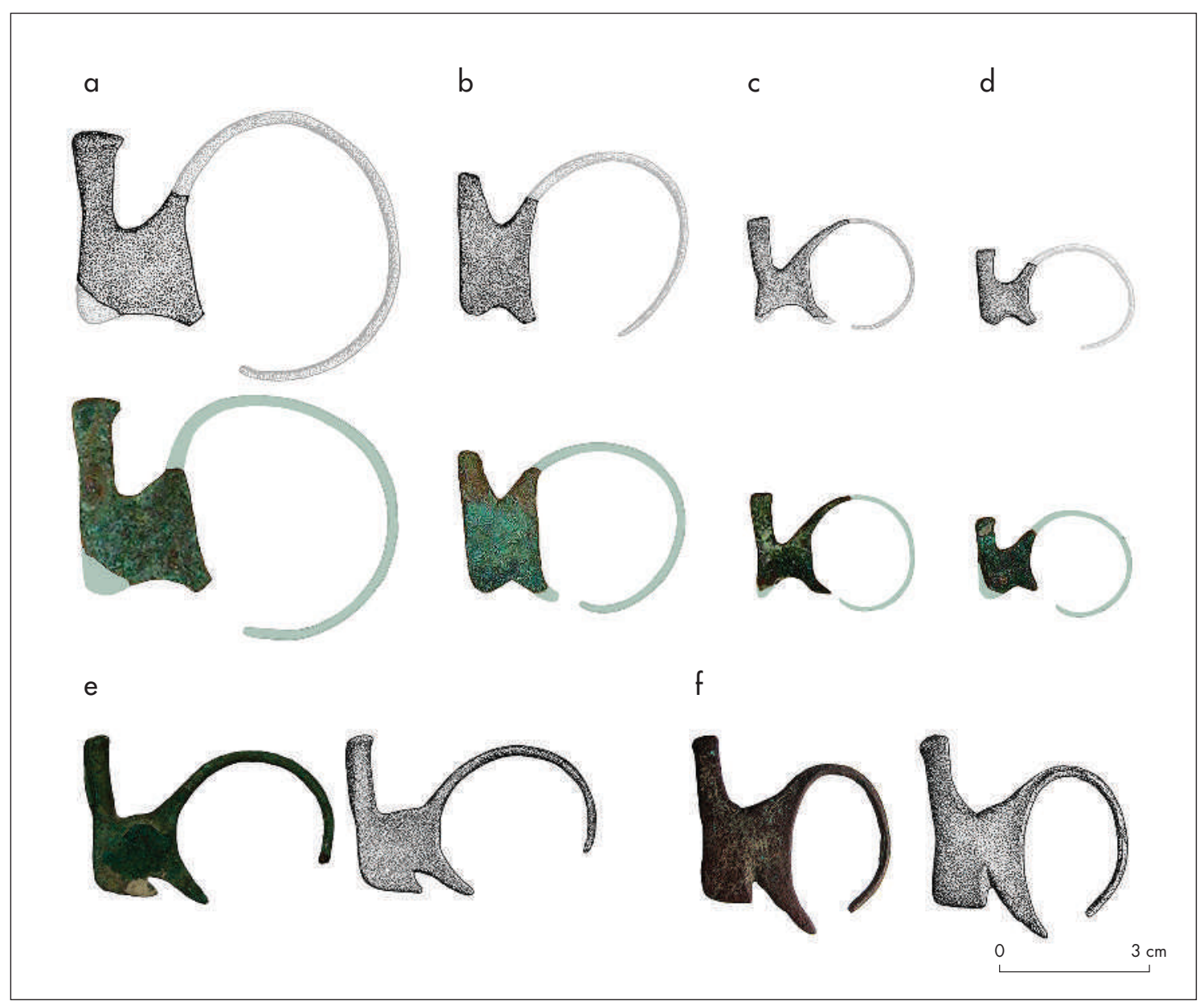

Figura 9. a-d) aros de subgrupos Zoomorfo $3 \mathrm{~b}$ y $3 \mathrm{c}$. Procedencia: Plaza Coquimbo; e-f) aros del subgrupo Zoomorfo 3c: e) Caldera; f) sin información (dibujos: Elvira Latorre; fotografías: María Ignacia Corral). Figure 9. a-d) Earrings from zoomorphic subgroup $3 b$ and 3c. Provenance: Plaza Coquimbo; $e$-f) Earrings from zoomorphic subgroup 3c. Provenance: $e$ ) Caldera; $f$ ) no information (drawings: Elvira Latorre; photos: María Ignacia Corral).

de un cuerpo pequeño que tiende a cuadrado con dos espirales levógiras menores como extremidades. En tanto, el subgrupo Zoomorfo $4 b$ tiene cuerpos grandes de lados rectos bien definidos y espirales pequeñas en sus vértices. En este caso se pierde en parte la lectura zoomorfa, aunque la orientación de las espirales sigue la misma lógica que el primer subgrupo, por lo que se mantuvo la etiqueta de zoomorfo (figs. 12c y 12d).

Otros tres ejemplares corresponden a casos especiales, entre los cuales se distingue una pieza donde el apéndice cuadrangular es un cilindro delgado que remata en un botón redondo (fig. 11a), un aro que porta un doble apéndice cuadrangular (fig. 11b) y un aro donde el cuerpo es curvado formando un tubo (fig. 11c). El primero guarda semejanza con el grupo Zoomorfo 2, aunque su cuerpo no presenta muescas, en tanto que el segundo muestra dos apéndices adyacentes y un cuerpo cuadrangular, que podrían interpretarse también como una representación zoomorfa de dos cabezas o dos animales. Ambas piezas se clasificaron como posibles zoomorfos, en tanto que la tercera permanece como un caso aislado.

El siguiente grupo se ha denominado Espirales unidireccionales. Está formado por 6 ejemplares (5,4\%) que muestran espirales levógiras de tamaño similar en su contorno sin otras modificaciones (fig. 12). En este grupo, cinco piezas presentan un cuerpo cuadrangular con tres espirales ubicadas en sus vértices libres y una 


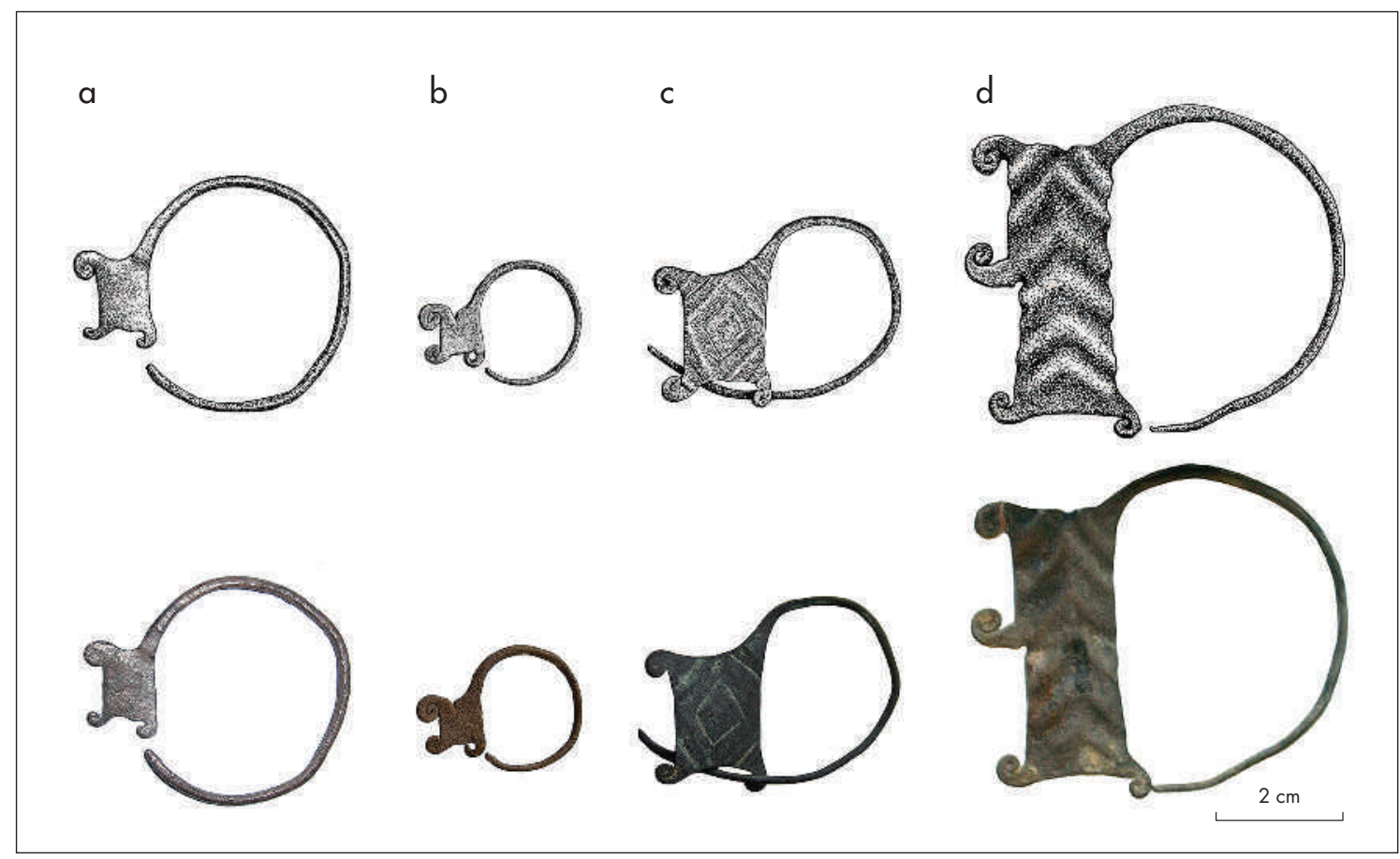

Figura 10: a-b) aros del subgrupo Zoomorfo 4a. Procedencia: a-b) EFo; c-d) zoomorfo 4b. Procedencia: c) Copiapó, y d) Fundo Titón (dibujos y fotografías: Elvira Latorre). Figure 10: $\boldsymbol{a}$-b) earrings from zoomorphic subgroup 4a. Provenance: $\boldsymbol{a}-\boldsymbol{b}$ ) EFO; $\boldsymbol{c}$ - $\boldsymbol{d}$ ) zoomorph $4 b$. Provenance: c) Copiapó and d) Fundo Titón (drawings and photos: Elvira Latorre).

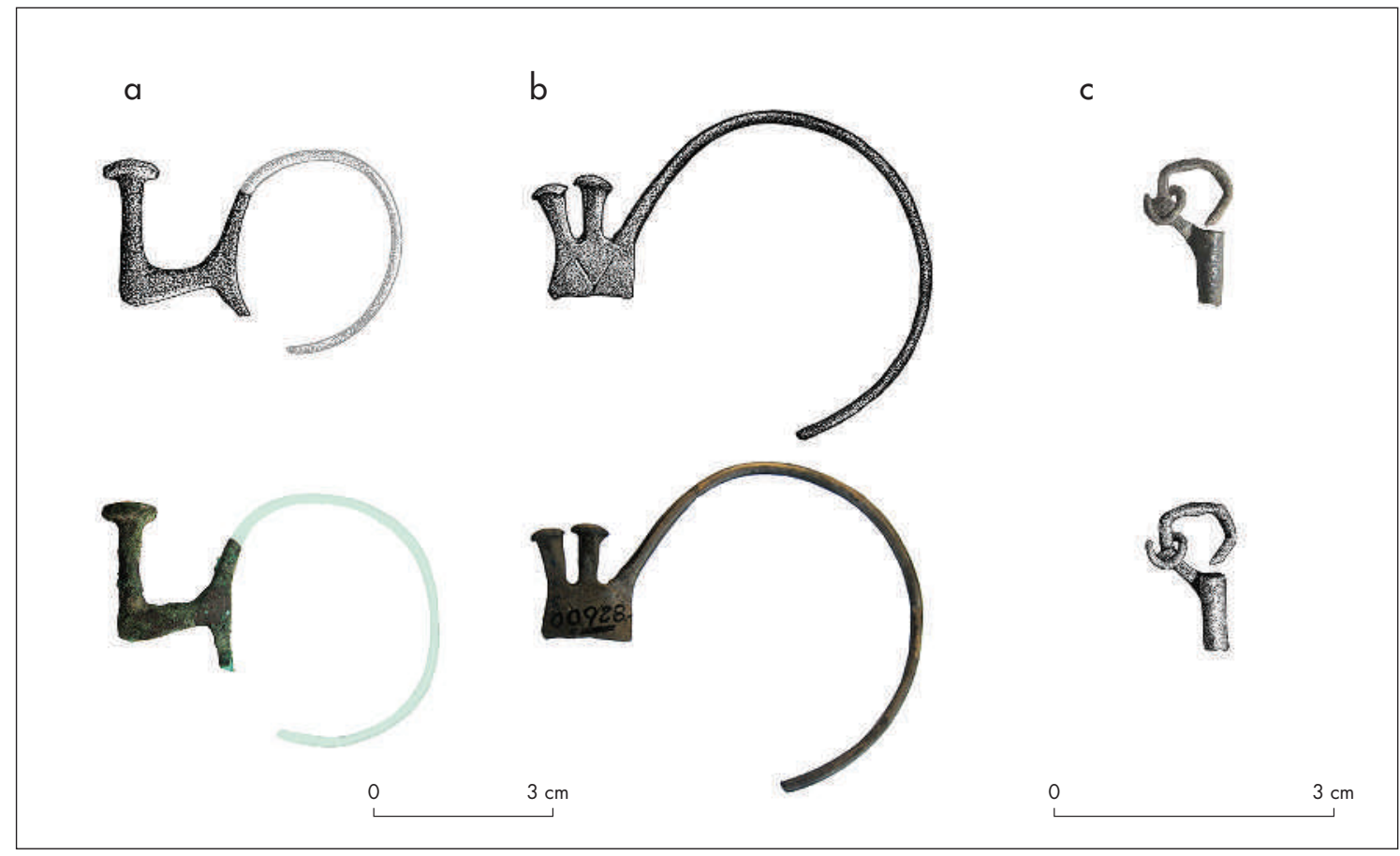

Figura 11: a-b) aros posibles zoomorfos; c) aro cuerpo tubo: a) Caldera; b) EFo; c) Plaza La Serena. Figure 11: $\boldsymbol{a}$-b) earrings from the 'possibly zoomorphic' group. Provenance: $\boldsymbol{a})$ Caldera; $\boldsymbol{b}$ ) EFO; $\boldsymbol{c}$ ) Single piece with tubular body. Provenance: Plaza La Serena. 


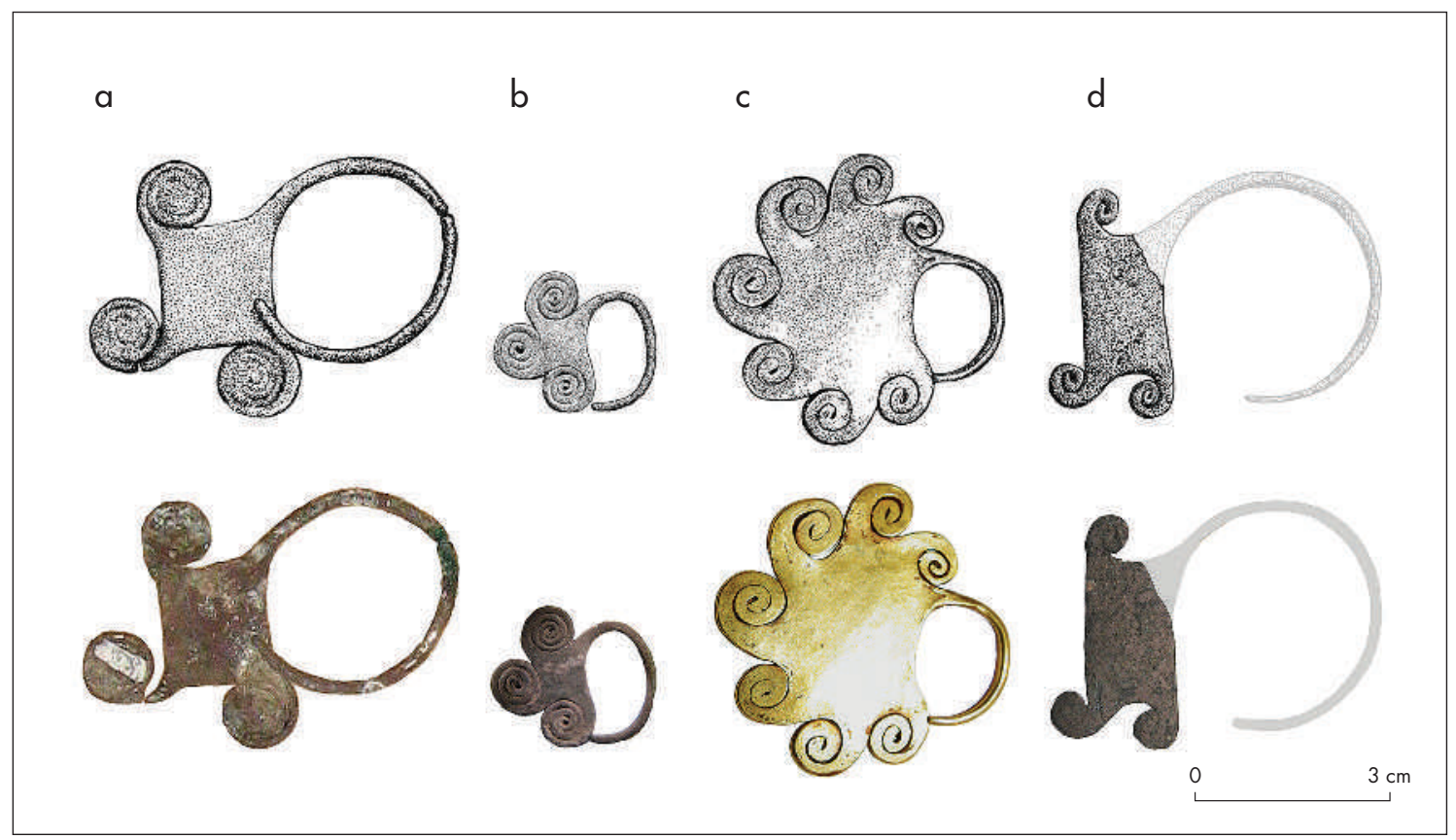

Figura 12. Aros del grupo Espirales unidireccionales: a) Plaza Coquimbo; b) La Puerta A; c) Caldera; d) sin información (fotografías a y b: María Ignacia Corral; fotografías y dibujos c y d: Elvira Latorre). Figure 12. Earrings from the unidirectional spiral group. Provenance: a) Plaza Coquimbo; $\boldsymbol{b}$ ) La Puerta A; $c$ ) Caldera; $d$ ) no information (photos a and $\boldsymbol{b}$ : María Ignacia Corral; photos and drawings $\boldsymbol{c}$ and d: Elvira Latorre).

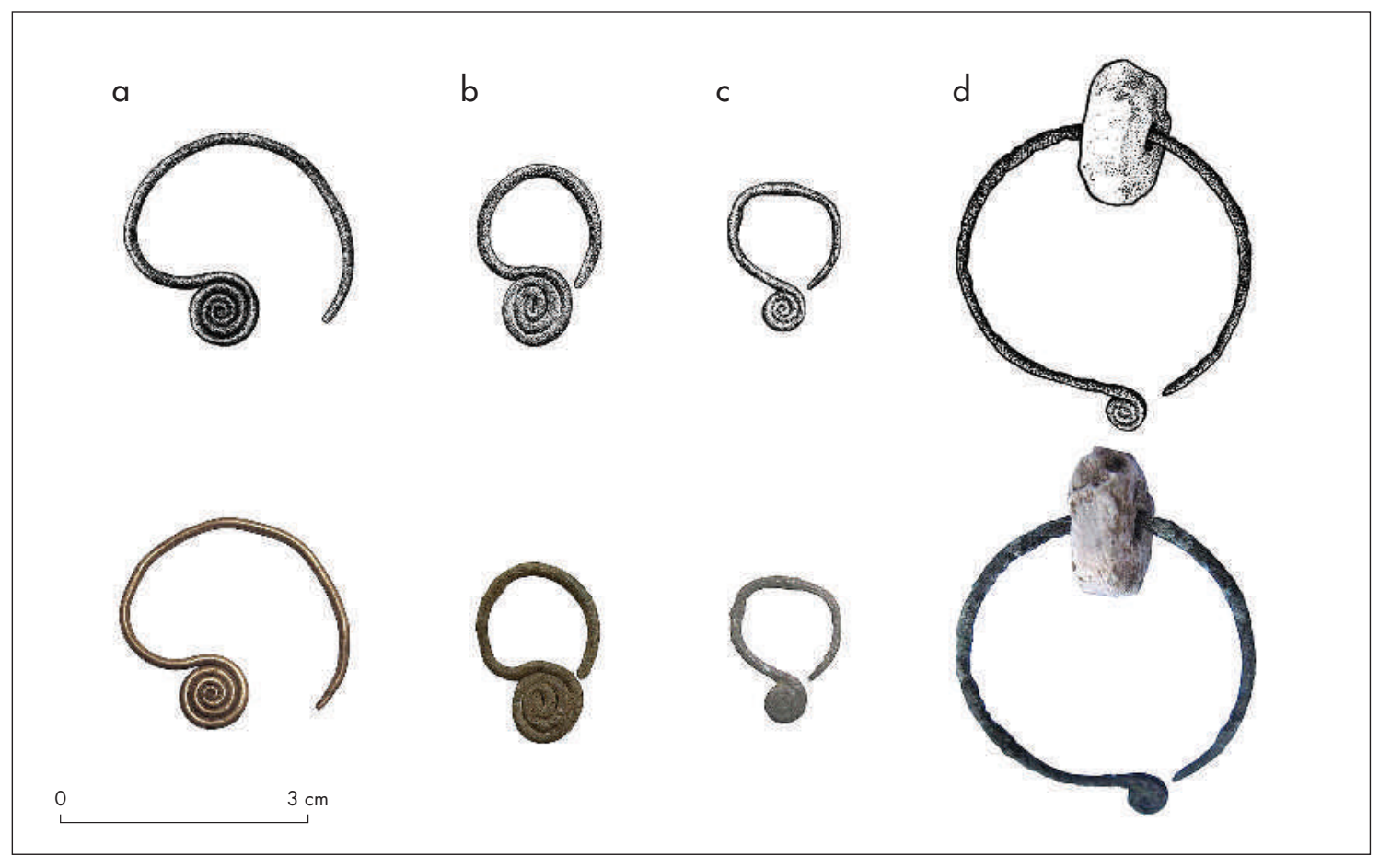

Figura 13. Aros de cuerpo simple: a) Los Mellizos; b) Plaza La Serena; c) Caldera; d) Planta Pisco Control. Figure 13. Earrings with simple body. Provenance: a) Los Mellizos; b) Plaza La Serena; c) Caldera; d) Planta Pisco Control. 
Tabla 3. Composición química de 11 aros del NSA, obtenida con pxrf. Los resultados de las piezas de oro son cuantitativos y se entregan de forma completa, ya que las piezas no presentan corrosión. En el resto de los aros había corrosión en la superficie, por lo cual los resultados son cualitativos y se expresan en rangos arbitrarios: ( ) no presente, (+) 0,1-0,9\%, (++) 1,0-9,9\%, (+++) 10-49,9\% y (++++) $\geq 50 \%$. Table 3. Chemical composition of 11 earrings from NSA, obtained with PXRF. The gold pieces displayed no corrosion and therefore the results are quantitative and complete. The rest of the earrings displayed surface corrosion, and as such the results are qualitative and expressed in the following arbitrary ranges: ( ) not present (+) 0.1-0.9\%, (++) 1.0-9.9\%, (+++) 10-49.9\% y $(++++) \geq 50 \%$.

\begin{tabular}{|c|c|c|c|c|c|c|c|c|c|}
\hline $\mathrm{N}^{o}$ & PIEZA & CÓDIGO MUSEO & METAL & $\mathrm{Cu} \%$ & As $\%$ & $\mathrm{Ag} \%$ & $\mathrm{Sn} \%$ & $\mathrm{Au} \%$ & TOTAL $\%$ \\
\hline 1 & Espiral única & CSY2539 & $\mathrm{Au}$ & 1,1 & & 23,3 & & 75,6 & 100 \\
\hline 2 & Espiral unidireccional & МСHАР 2610 & $\mathrm{Au}$ & 2,4 & & 20,0 & & 77,5 & 100 \\
\hline 3 & Zoomorfo la & CsY 2540 & $\mathrm{Au}$ & 1,7 & & 47,4 & & 50,9 & 100 \\
\hline 4 & Zoomorfo 1a & CsY2494 & $\mathrm{Ag}$ & ++ & & ++++ & & & \\
\hline 5 & Zoomorfo la & CsY2495 & $\mathrm{Ag}$ & & & ++++ & & & \\
\hline 6 & Zoomorfo 1a & CsY2499 & $\mathrm{Cu}+\mathrm{As}$ & ++++ & ++ & & & & \\
\hline 7 & Zoomorfo la & CsY2496 & $\mathrm{Cu}+\mathrm{Sn}$ & ++++ & & & +++ & & \\
\hline 8 & Zoomorfo la & Csy2496-b & $\mathrm{Cu}+\mathrm{Sn}$ & ++++ & & & +++ & & \\
\hline 9 & Zoomorfo $3 c$ & CsY2501 & $\mathrm{Cu}+\mathrm{Sn}$ & ++++ & & & +++ & & \\
\hline 10 & Espiral única & CsY 2500 & $\mathrm{Ag}$ & & & ++++ & & & \\
\hline
\end{tabular}

pieza única tiene un cuerpo ovalado en torno al cual se posicionan siete espirales (fig. 12c).

El último grupo se denominó Espiral único, y agrupa los aros formados por un arco y una espiral levógira como únicos elementos mínimos (fig. 13). Se trata del grupo más numeroso, pues reúne 30 ejemplares (26,8\%).

Los dos grupos anteriores estarían marcando una diferencia con los precedentes, ya que la organización de los elementos mínimos no estaría respondiendo a la misma lógica que los Zoomorfos. Estas piezas podrían corresponder a signos no icónicos, pero también podrían asociarse a referentes externos con una simetría distinta, como organismos marinos, elementos del mundo vegetal $\mathrm{u}$ otros.

\section{Metales}

Los aros fueron fabricados en cobre o aleaciones de base cobre, plata o en base plata y oro o de base oro (tabla 3). Solo dos ejemplares poseen análisis previos de com- posición química elemental que permiten determinar su materia prima, al menos a un nivel cuantitativo de presencia/ausencia de elementos (Latorre 2011, Troncoso et al. 2012), en tanto que otros once, depositados en el MCHAP, fueron analizados en el marco del presente estudio mediante un equipo de fluorescencia de rayos x portátil (pXrf). A partir de los resultados se identificaron tres aros en oro con diversos porcentajes de plata, respecto de los cuales, análisis de depósitos primarios y secundarios de este metal en Sudamérica han detectado rangos de plata que varían entre 5\% y 30\% (Chapman et al. 2002, Hérail et al. 1999). Esto indica que el 20-23\% de plata presente en las piezas 2539 y 2610 podría corresponder a oro nativo con altos niveles de plata; mientras que el $47 \%$ de plata en el aro 2540 correspondería a una aleación intencional de plata y oro.

Otras tres piezas fueron fabricadas en plata, dos de ellas sin alear, mientras que el aro 2494 contiene entre 1 a $10 \%$ de cobre. La plata nativa puede contener cobre entre 0,08-3\% (Murillo-Barroso et al. 2014), hasta un 18\%. Sin 
Tabla 4. Cantidades de aros por metal y tipo de representación. Table 4. Number of earrings by type of metal and representation.

\begin{tabular}{|c|c|c|c|c|c|c|c|c|c|c|}
\hline GRUPO/SUBGRUPO & 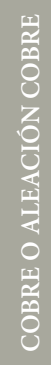 & 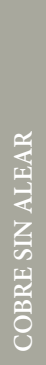 & 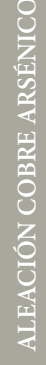 & 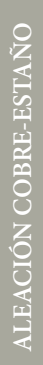 & 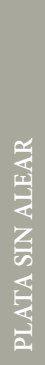 & 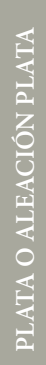 & $\begin{array}{l}\frac{a}{4} \\
\frac{1}{y} \\
\frac{1}{4} \\
z \\
5 \\
0 \\
0 \\
0\end{array}$ & 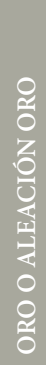 & 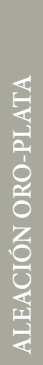 & $\underset{\mathrm{E}}{\stackrel{\Xi}{\leftrightarrows}}$ \\
\hline Zoomorfo la & & & 1 & 2 & 2 & 11 & & & 1 & 17 \\
\hline Zoomorfo 2 & 18 & & & & & 1 & & & & 19 \\
\hline Zoomorfo $3 b$ & 4 & & & & & & & & & 4 \\
\hline Posible zoomorfo & 1 & & & & & 1 & & & & 2 \\
\hline Zoomorfo $1 \mathrm{~b}$ & 9 & & & & & 1 & & 1 & & 11 \\
\hline Zoomorfo 4a & 3 & & & & & 1 & & & & 4 \\
\hline Zoomorfo $3 \mathrm{a}$ & 6 & 2 & & & & 1 & & & & 9 \\
\hline Zoomorfo 3c & & & & 1 & & 1 & & & & 2 \\
\hline Zoomorfo $4 \mathrm{~b}$ & 3 & & & & & 3 & & 1 & & 7 \\
\hline Espiral único & 23 & & & & 2 & 3 & 1 & 1 & & 30 \\
\hline Espirales unidireccionales & 1 & & & & & 4 & 1 & & & 6 \\
\hline Tubo & & & & & 1 & & & & & 1 \\
\hline TOTAL & 68 & 2 & 1 & 3 & 5 & 27 & 2 & 3 & 1 & 112 \\
\hline
\end{tabular}

embargo, en España se han detectado objetos con 20\% de cobre, incluido naturalmente en la plata (Murillo-Barroso et al. 2014). El aro 2499 contiene bajas cantidades de arsénico. Depósitos de cobre con impurezas de arsénico no son extrañas en el norte y centro de Chile (latitud $\left.18-34^{\circ} \mathrm{S}\right)$, lo que podría demostrar el uso de minerales locales o de zonas aledañas. En cuanto al estaño presente en los aros 1184, 2496, 2496-b y 2501, los depósitos de este recurso se encuentran únicamente en el Noroeste Argentino y en Bolivia, por lo cual representaría el uso de metales importados (Lechtman \& Macfarlane 2005; Maksaev et al. 2007), más que al traslado de piezas desde otras áreas, debido a la ausencia de este tipo de objetos en las áreas antes referidas.
Las piezas restantes fueron clasificadas en categorías operativas a partir de rasgos observables a simple vista. De manera general, un 66,1\% ( $n=74)$ de las piezas están fabricadas en cobre o aleaciones de base cobre, un 28,6\% $(n=32)$ en plata o aleaciones de base plata y un $5,4 \%$ $(n=6)$ en oro o aleaciones base oro (tabla 4).

Sin contar los Zoomorfos 3c, fabricados exclusivamente en cobre o aleaciones de base cobre, todos los tipos definidos representados por más de un ejemplar están fabricados al menos en cobre-aleaciones de base cobre y plata-aleaciones de base plata. Así mismo, en la mayoría domina el uso del cobre sobre la plata, con excepción de los Zoomorfos 4b, que tienen cantidades similares, y los de tipo Espirales unidireccionales con 
Tabla 5. Cantidades de aros por tipo, cronología, cuenca y sitio/localidad de procedencia. Table 5. Number of earrings by type, chronology, basin and site/locality of provenance.

\begin{tabular}{|c|c|c|c|c|c|c|c|c|c|c|c|c|c|c|c|}
\hline CUENCA & CRONOLOGÍA & SITIO/ LOCALIDAD & \begin{tabular}{l}
$\nwarrow$ \\
0 \\
0 \\
\multirow{2}{*}{} \\
0 \\
$\sum_{0}$ \\
0 \\
0
\end{tabular} & $\begin{array}{l}0 \\
0 \\
0 \\
0 \\
0 \\
0 \\
0 \\
0 \\
0\end{array}$ & 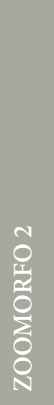 & 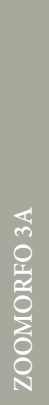 & 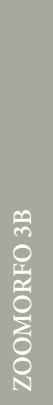 & 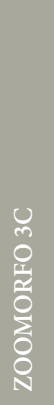 & 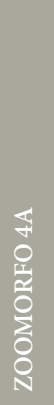 & 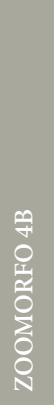 & 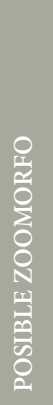 & 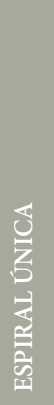 & 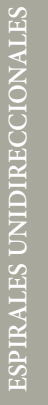 & 嗢 & ఏ \\
\hline \multirow{9}{*}{ Copiapó } & PM & La Puerta A & & & 2 & & & & & & & & 3 & & 5 \\
\hline & PMt & Iglesia Colorada & & & 2 & & & & & & & & & & 2 \\
\hline & \multirow{5}{*}{$\begin{array}{l}\text { Probable } \\
\text { PT }\end{array}$} & Bahía Salada & & 1 & & & & & & & & & & & 1 \\
\hline & & Caldera & & 1 & 10 & & & 1 & & & 1 & 2 & 1 & & 16 \\
\hline & & Costa Copiapó & & & & & & & & & & 1 & & & 1 \\
\hline & & Hornitos & & 1 & & & & & & 1 & & 1 & & & 3 \\
\hline & & $\begin{array}{c}\text { Punta Numwich } \\
\text { (sIC, Punta Numwick) }\end{array}$ & & & & 1 & & & & & & & & & 1 \\
\hline & \multirow{2}{*}{ Indet. } & Copiapó & & & & & & & & 1 & & 1 & & & 2 \\
\hline & & Costa Copiapó & & & & 1 & & & & & & & & & 1 \\
\hline \multirow{7}{*}{ Elqui } & PIT & Punta Teatinos & & & & & & & & & & 2 & & & 2 \\
\hline & \multirow{2}{*}{$\mathrm{PM}$} & Plaza Coquimbo & & & & 4 & 4 & & & & & 7 & 1 & & 16 \\
\hline & & Plaza La Serena & & & & 2 & & & & & & 1 & & 1 & 4 \\
\hline & PT & Fundo Coquimbo & & 2 & & & & & & 1 & & 1 & & & 4 \\
\hline & \multirow{2}{*}{$\begin{array}{l}\text { Probable } \\
\text { PT }\end{array}$} & Altovalsol & & 1 & & & & & & & & & & & 1 \\
\hline & & Fundo Titón & & & & & & & & 2 & & & & & 2 \\
\hline & Indet. & Huanta & & & & 1 & & & & & & & & & 1 \\
\hline \multirow{3}{*}{ Limarí } & \multirow{2}{*}{ PT } & $\begin{array}{l}\text { Estadio Fiscal de Ovalle } \\
\text { (EFO) }\end{array}$ & & 3 & 3 & & & & 2 & & 1 & 3 & & & 12 \\
\hline & & $\begin{array}{l}\text { Planta Pisco Control } \\
\text { (PPC) }\end{array}$ & & 2 & & & & & 2 & 1 & & 8 & & & 13 \\
\hline & Indet. & Barraza & 1 & & & & & & & & & & & & 1 \\
\hline Choapa & РАТ & Los Mellizos & & & & & & & & & & 1 & & & 1 \\
\hline Indet. & & Indet. & 16 & & 2 & & & 1 & & 1 & & 2 & 1 & & 23 \\
\hline \multicolumn{3}{|c|}{ TOTAL } & 17 & 11 & 19 & 9 & 4 & 2 & 4 & 7 & 2 & 30 & 6 & 1 & 112 \\
\hline
\end{tabular}


tres espirales y los Zoomorfos 1a, en los que es más frecuente la plata. En este último subgrupo se encuentra la mayor diversidad, con el uso de las aleaciones de cobre/ arsénico, cobre/estaño, oro/plata y plata-aleaciones base plata; sin embargo, es también el tipo que cuenta con más piezas analizadas.

\section{DISTRIBUCIÓN ESPACIAL Y CRONOLÓGICA}

En la etapa posterior se procuró determinar la distribución de los grupos y subgrupos, a pesar de contar con información incompleta sobre su procedencia geográfica y adscripción cronológica. En la muestra analizada, solo del 40,2\% ( $\mathrm{n}=45)$ existe precisión respecto de sitio y período, en tanto que del $39,3 \%(n=44)$ se tiene información incompleta y/o tentativa y del 20,5\% $(n=23)$ no hay ningún dato asociado.

Entre los Zoomorfos 1a, una mayoría carece de información contextual, aunque su homogeneidad interna podría informar que proceden de una misma localidad. A esto se suma un aro procedente de la localidad de Barraza en la cuenca del Limarí, de cronología indeterminada. En cuanto a los Zoomorfos 1b, en su mayor parte proceden del PT de la cuenca del Limarí $\left(30^{\circ} 15^{\prime}\right.$ y $31^{\circ} 20^{\prime}$, latitud Sur), específicamente de los sitios PPC y EFO. También hay registros de algunos ejemplares procedentes de sitios contemporáneos de la cuenca del Elqui $\left(29^{\circ} 35^{\prime}\right.$ y $30^{\circ} 20^{\prime}$, latitud Sur), como Fundo Coquimbo y Altovalsol, y dos piezas procedentes de la cuenca de Copiapó, probablemente asignables al PT y que incluyen el único aro figurativo.

Los Zoomorfos 2 se concentran en la cuenca de Copiapó, procedentes tanto de La Puerta A, sitio adscrito al complejo Ánimas, como de Iglesia Colorada, señalado como Tardío (Niemeyer et al. 1998), además de numerosos ejemplares provenientes de Caldera, probablemente asociados a piezas del dominio inca (Latorre et al. 2007). Sin embargo, también se encuentran Zoomorfos 2 en la cuenca del Limarí. En tanto, los aros Zoomorfos 3a aparecen principalmente en dos sitios del PM de la cuenca del Elqui: Plaza Coquimbo y Plaza La Serena, aunque se registran ejemplares sin información contextual procedentes tanto de la cuenca del Elqui como de Copiapó. A su vez, los Zoomorfos 3b se localizarían exclusivamente en Plaza Coquimbo, mientras que entre los Zoomorfos $3 \mathrm{c}$ se cuenta un ejemplar procedente de
Caldera (cuenca de Copiapó), probablemente asociado a material del PT, junto a una pieza que carece de información. Los Zoomorfos 4a y los Zoomorfos $4 \mathrm{~b}$ se ubican en contextos tardíos, los primeros solo en los sitios PPC y EFo de la cuenca del Limarí y los segundos en Fundo Coquimbo y PPC, junto a ejemplares aislados de cronología indeterminada hallados en las cuencas del Elqui y Copiapó.

Los aros con espirales unidireccionales se observan solo en los sitios Ánimas de La Puerta A y Plaza Coquimbo, aun cuando se documenta una pieza procedente de Caldera que podría asociarse con un momento tardío. Por último, los aros con espiral única están presentes a través de toda la secuencia alfarera, desde la única pieza PAT hasta ejemplares tardíos del Estadio Fiscal de Ovalle y Planta Pisco Control. Espacialmente, se distribuyen entre las cuencas de Copiapó y Choapa, aunque se concentrarían en las cuencas del Elqui y Limarí, donde son abundantes tanto en Plaza Coquimbo, sitio Ánimas, como en PPC, adscrito al PT (tabla 5).

\section{ANIMALES METÁLICOS}

Si bien se ha propuesto que cuatro grupos de aros corresponden a representaciones zoomorfas, queda por definir si es posible asociarlos a animales específicos. En este sentido, se observa que, tanto los Zoomorfos 1a como los Zoomorfos 2 y los Zoomorfos 3 b y $3 c$ presentan rasgos tales como un cuello largo con una cabeza pequeña, los que en otros soportes se asocian a camélidos. Estos grupos corresponden a la representación zoomorfa más frecuente y la que muestra una mayor variedad de combinaciones, presentando además una amplia dispersión espacial y cronológica. Los camélidos son motivos recurrentes en las manifestaciones visuales de diversas poblaciones prehispánicas, dando cuenta de su importancia tanto simbólica como económica (González 2002, Gallardo \& Yacobaccio 2007, Troncoso 2012); en el NSA se representan en el arte rupestre y en vasijas cerámicas, además de su uso como ofrendas en contextos funerarios tanto del PM como Diaguita temprano (Castillo 1989, Troncoso 2012, Troncoso et al. 2016b).

En este sentido, aunque inicialmente se pensó que estas representaciones visuales daban cuenta de un manejo de camélidos domésticos que se remontaría al PAT (Castillo 1989, Niemeyer et al. 1998), estudios posteriores han ido relativizando este supuesto. Nuevas aproximaciones 
al arte rupestre muestran que muchos de los camélidos del estilo La Silla, tradicionalmente considerado PAT, si bien serían domésticos, tendrían una asignación al PIT y especialmente al PT (Troncoso 2012). Por otra parte, análisis zooarqueológicos de camélidos depositados como ofrendas en Plaza La Serena y Plaza Coquimbo evidencian que se trata de animales sin una clara asignación a especies domésticas (Becker \& Cartajena 2005). Igualmente, para sitios del valle de Mauro se propone que los camélidos domésticos recién aparecerían en el PIT, pudiendo en ese momento coexistir con especies silvestres (principalmente guanacos), mientras que las llamas cargueras llegarían solo tras la incorporación del semiárido al Tawantinsuyu (López et al. 2015). En tanto, para el área septentrional del NSA se ha sugerido que la introducción de camélidos domésticos es temprana (Niemeyer et al. 1998, Troncoso et al. 2016b), aunque no existen análisis estrictos que lo sustenten.

Los aros zoomorfos de características relacionadas con camélidos, al registrarse en toda la secuencia, pueden estar representando tanto especies silvestres como domésticas, aunque su aparente aumento hacia el PT podría indicar que su referente cambia hacia camélidos domésticos, lo que sería coherente con la propuesta de Troncoso (2012) para el arte rupestre, con la fuerte introducción de estos animales en el mismo período (López et al. 2015), y por su importancia económica y simbólica en el mundo incaico y andino en general. Asimismo, su concentración hacia la cuenca de Copiapó coincidiría con la recurrencia de la representación de camélidos en la cerámica, que se ha relacionado con la creación y mantención de una identidad local (Garrido 2007). No obstante, son escasas las piezas con buena información de contextos, por lo que estas tendencias deben examinarse con cautela.

Los Zoomorfos 3a muestran un cuello largo, junto a un gran cuerpo donde muescas marcan protuberancias que podrían ser extremidades con una forma central similar a la cola de un ave. Las aves tienen antecedentes más difíciles de rastrear, aunque son una representación recurrente en el NSA, materializada especialmente en vasijas cerámicas (Cornejo 1989, Troncoso et al. 2016a). Sin embargo, es posible observar que son abundantes durante el PM, para posteriormente disminuir o desaparecer, lo que puede indicar un cambio en la importancia simbólica de este referente. Los aros zoomorfos que no adscribimos a una especie en particular pueden corresponder a roedores, felinos, cánidos u otros durante el
PT. Al respecto, resulta interesante para este período que el registro arqueofaunístico en el NSA se diversifica enormemente en comparación con los períodos anteriores, e incluye una gran variedad de especies de distintos tamaños, las cuales no fueron usadas con fines netamente alimenticios y tecnológicos, mientras que datos etnohistóricos asocian su uso también a ritos, rogativas, e incluso como medicinas (López et al. 2015, Miyano et al. 2017).

\section{CONCLUSIONES}

El análisis de los elementos mínimos mostró que estos se limitan a pocos componentes que se combinan según reglas fijas, generando un número finito de grupos con elementos similares en posiciones similares. $\mathrm{Al}$ abordar estas reglas, se observó que un primer nivel norma cómo se combinan dichos elementos, mientras que un segundo nivel determinaría qué se quiere representar mediante esa combinación. Ambos niveles obedecen a una intención subyacente de representar en los aros un referente de tipo zoomorfo en la mayoría de los casos. De acuerdo con esto, en el primero se distinguen seis grupos de combinaciones, que en el segundo podrían estar representando camélidos, aves y otros zoomorfos indeterminados, además de piezas de espiral única y de espirales unidireccionales que pueden tener un referente animal o vegetal que desconocemos.

Ambos niveles presentan tendencias en sus distribuciones cronológicas y espaciales, observándose que las piezas más tempranas, que se remontan al PM, representan tanto aves como camélidos con apéndices cuadrangulares por cabeza y cuello, junto a un cuerpo donde las extremidades son delineadas por muescas, mientras que las espirales están presentes, pero se utilizan en piezas no zoomorfas. En tanto, para los aros tardíos, las aves disminuyen o desaparecen, habría un aparente aumento de los camélidos y aparece un nuevo referente, los cuadrúpedos indeterminados. En sus contornos, cabezas y cuellos están marcados tanto por apéndices cuadrangulares como por espirales, y sus extremidades dibujadas mayormente por espirales. Espacialmente, los camélidos tienden a ser más abundantes en la cuenca de Copiapó y los cuadrúpedos indeterminados en la cuenca del Limarí; no obstante, cabe destacar que las piezas se concentran en sitios específicos, por lo que esta tendencia podría darse más a nivel de sitio que de cuenca; aun así, 
cada grupo y referente tendría ejemplares dispersos a través de las distintas cuencas del NSA.

Por otra parte, y considerando estas diferencias, los elementos de diseño y su organización se mantendrían a través de un lapso y dentro de un área geográfica donde otros aspectos de la cultura material van variando significativamente, especialmente la alfarería. La mantención de estos patrones y de un mismo estilo de representación daría cuenta de una base ideológica común al NSA, que se mantiene desde el PM hasta la llegada del español, y que el Tawantinsuyu no afecta, sino que probablemente potencia y aumenta.

Finalmente, los aros deben ser entendidos no solo como objetos metálicos caracterizados por una determinada tecnología de producción y manufactura sino también por la función para la cual fueron diseñados: como ornamentos. Tal como propone Soto (2015) para los objetos perforados del Norte Grande, son elementos visuales añadidos al cuerpo, destinados a causar efectos en su entorno y están formando parte del lenguaje corporal de quienes los portan, sumando a sus características visuales otras conferidas por el uso, como movimiento, brillo cambiante y sonido.

Nuevos hallazgos bien documentados y el análisis de contextos productivos minero-metalúrgicos pueden variar y enriquecer la comprensión sobre estas piezas que parecen ser emblemáticas de poblaciones alfareras del NSA, y proponer hipótesis sobre su funcionamiento en la sociedad como animales metálicos que son portados por determinadas mujeres y las acompañan a la tumba.

Agradecimientos Comprometen nuestro agradecimiento por permitirnos el acceso a colecciones y piezas los y las colegas Varinia Varela, Pablo Larach, Andrés Troncoso y Pilar Rivas. Igualmente, agradecemos a las colegas María Ignacia Corral y Catalina Gutiérrez por compartir datos e imágenes, y a los y las evaluadores cuyos comentarios ayudaron a mejorar el manuscrito.

\section{NOTAS}

${ }^{1}$ Piezas con los siguientes números de inventario: CSY1433 a, CSY2485; CSY2486; CSY2487; CSY2488; CsY2490; CSY2492; CSY2493; CSY2494; CSY2495; CsY2497; CsY2499; CSY2500; CsY2501; CsY2536; CsY2539; CsY, CsY2496 a y b, y MCHAP2610.

\section{REFERENCIAS}

BALESTA, B. 2015. Interpretaciones semióticas sobre imágenes de camélidos en el Noroeste Argentino. Boletín del Museo Chileno de Arte Precolombino 20 (1): 9-28. Santiago.

Becker, C. \& Cartajena, I. 2005. Las ofrendas de camélidos en el cementerio de la Plaza Coquimbo, una nueva mirada. Fondo de Apoyo a la Investigación Patrimonial. Informes, pp. 77-86.

Berón, M. \& GonzÁlez, L. 2006. Análisis de composición de adornos metálicos de un contexto funerario de cazadores recolectores. El sitio Chenque I, provincia de La Pampa. En Metodologías científicas aplicadas al estudio de los bienes culturales, A. Pifferetti \& R. Bolmaro, Eds., pp. 82-86. Rosario: Humanidades y Artes Ediciones.

Campbell, R. 2004. El trabajo de metales en la Araucanía (siglos X-XVII DC). Tesis para optar al título de Arqueólogo, Departamento de Antropología, Universidad de Chile, Santiago.

CAmpbell, R. 2015. Entre El Vergel y la platería mapuche: el trabajo de metales en la Araucanía postcontacto (15501850 DC). Chungara 47 (4): 621-644. Arica.

CAmpbell, R. \& Latorre, E. 2003. Rescatando una materialidad olvidada: síntesis, problemáticas y perspectivas en torno al trabajo prehispánico de metales de Chile Central. Boletín de la Sociedad Chilena de Arqueología 35/36:47-61. Santiago.

Castillo, G. 1989. Agricultores y pescadores del Norte Chico: el complejo Las Ánimas (800 a 1200 DC). En Prehistoria, desde sus orígenes hasta los albores de la conquista, J. Hidalgo, V. Schiappacasse, H. Niemeyer, C. Aldunate \& I. Solimano, Eds., pp. 265-276. Santiago: Andrés Bello.

Cornejo, L. 1989. El plato diaguita: variabilidad y especificidad. Boletín del Museo Chileno de Arte Precolombino 3: 47-80. Santiago.

Cornely, F. 1956. Cultura diaguita chilena y cultura El Molle. Santiago: Pacífico.

Corral, M. 2009. Caracterizando los objetos metálicos del complejo cultural Ánimas, norte semiárido de Chile. Tesis para optar al grado de Licenciada en Arqueología y título de Arqueóloga, Facultad de Educación y Cultura, Universidad Internacional SEK, Santiago.

Corral, M. 2012. Caracterizando los objetos metálicos del complejo cultural Ánimas, norte semiárido de Chile. Actas del XvirI Congreso Nacional de Arqueología Chilena: 269-276. Santiago.

Chapman, R.J., Leake, B. \& Styles, M., 2002. Microchemical characterization of alluvial gold grains as an exploration tool. Gold Bulletin 35(2): 53-65. Berlín: Springer-Verlag.

Dobres, M. \& Hoffman, CH. 1994. Social agency and the dynamics of prehistoric technology. Journal of Archaeological Method and Theory 1 (3): 211-258. Kimberley.

Dobrez, L. \& Dobrez, P. 2014. Canonical figures and the recognition of animals in life and art. Boletín del Museo Chileno de Arte Precolombino 19 (1): 9-22. Santiago. 
Gallardo, F. \& Yacobaccio, H. 2007. ¿Silvestres o domesticados? Camélidos en el arte rupestre del Formativo Temprano en el desierto de Atacama (norte de Chile). Boletín del Museo Chileno de Arte Precolombino 12 (2): 9-31. Santiago.

GARrido, F. 2007. El camélido sagrado y el hombre de los valles: una aproximación a la cultura Copiapó y sus relaciones a partir de la alfarería. Tesis para optar al título de Arqueólogo, Departamento de Antropología, Universidad de Chile, Santiago.

Gell, A. 1992. The technology of enchantment and enchantment of technology. En Anthropology, art and aesthetics, J. Coote \& A. Shelton, Eds., pp. 40-66. Oxford: Clarendon Press.

GeLL, A. 1998. Art and agency: an anthropological theory. Oxford: Clarendon Press.

GonZÁLEZ, J. 2002. Etología de camélidos y arte rupestre en la subregión río Salado (norte de Chile, II Región). Estudios Atacameños 23: 23-32. San Pedro de Atacama.

GonzÁlez, L. 2004. Bronces sin nombre: la metalurgia prehispánica en el Noroeste Argentino. Buenos Aires: Fundación CEPPA.

GosDen, Сн. 2001. Making sense: archaeology and aesthetics. World Archaeology 33 (2): 163-167. Durham.

Gosden, CH. 2005. What do Objects want? Journal of Archaeological Method and Theory 12 (3): 193-211.

GuAJARDo, A. 2011. El complejo cultural Ánimas y sus vínculos con la cultura Diaguita en la Región de Coquimbo: una visión desde la alfarería. Memoria para optar al título de Arqueóloga, Departamento de Antropología, Universidad de Chile, Santiago.

Gutiérrez, C. 2012. “El alma de los metales". Producción tecnológica de piezas metálicas en el litoral de la Región de Atacama. Memoria para optar al título de Arqueóloga, Departamento de Antropología, Universidad de Chile, Santiago.

Hérail, G., Lagos, J. \& Vivallo, W. 1999. Gold dispersion in Andean desert environments (Atacama, Chile). Journal of Geochemical Exploration, 66 (3): 427-439. Amsterdam: Elsevier.

LAtorre, E. 2006. Trabajo de metales tempranos en Chile central. Werken 8: 77-90. Santiago.

LATORRe, E. 2009. De adornos y herramientas nacidos del fuego: una caracterización del trabajo en metales en la cultura Diaguita (ca. 800-1536 DC). Memoria para optar al título de Arqueóloga, Departamento de Antropología, Universidad de Chile, Santiago.

LAtorre, E. 2011 Ms. Informe de análisis del material metálico del sitio Plaza La Serena. Informe para Estudio de Impacto Ambiental estacionamientos subterráneos Plaza de Armas de La Serena.

LATORre, E. \& López, P. 2011. Los metales en la cultura Diaguita chilena (ca. 900-1536 DC): una aproximación metodológica e interpretativa. Intersecciones en Antropología 155-167. Buenos Aires.
Latorre, E., Plaza, M. T. \& Riveros, R. 2007. El caso de la colección Lodwig: caracterización de un conjunto de piezas metálicas prehispanas del litoral de Caldera (III Región, Chile). Werken 11: 89-105. Santiago.

Lechtman, H. 1979. Issues in Andean metallurgy. En PreColumbian metallurgy of South America, E. Benson, Ed., pp: 1-40. Washington: Dumbarton Oaks.

Lechtman, H. \& Macfarlane, A., 2005. La metalurgia del bronce en los Andes Sur Centrales: Tiwanaku y San Pedro de Atacama. Estudios Atacameños 30: 7-27. San Pedro de Atacama.

López, P., Cartajena, I., Santander, B., Pavlovic, D. \& Pascual, D. 2015. Camélidos domésticos en el valle de Mauro (norte semiárido, Chile): múltiples análisis para un mismo problema. Intersecciones en Antropología 16: 101-114. Buenos Aires.

López, P., Latorre, E., Pavlovic, D., Alfaro, S., Belmar, C., Gómez, P. \& Plaza, M. 2017. Pequeñas tumbas en la colina: aportes al conocimiento del Período Alfarero Temprano en el valle de Mauro ( $31^{\circ} \mathrm{S}$ ) desde la funebria. Estudios Atacameños 54: 65-84. San Pedro de Atacama.

Magariños de Morentín, J. 2001. La(s) semiótica(s) de la imagen visual. Cuadernos FHyCS-UNJu 17: 295-320. Jujuy.

Maksaev, V., Townley, B.K., Palacios, C. \& Camus, F., 2007. Metallic ore deposits. En The geology of Chile, T. Moreno \& W. Gibbons, Eds., pp. 179-199. London: The Geological Society.

Mera, R., Mille, B., Munita, D. \& Figueroa, V. 2015. Cooper earrings in La Araucanía: earliest evidence of metal usage in southern Chile. Latin American Antiquity 26 (1): 106-119. Cambridge.

Miyano, J., Lantos, I., Ratto, N. \& Orgaz, M. 2017. Animales e Incas en el oeste Tinogasteño (Catamarca, Argentina). Latin American Antiquity 28 (1): 28-45. Cambridge.

Montané, J. 1960. Arqueología diaguita en conchales de la costa: Punta de Teatinos. Publicaciones del Museo y de la Sociedad Arqueológica de La Serena. Boletín 11: 68-75. La Serena.

Murillo-Barroso, M., Montero-Ruiz, I., \& Bartelheim, M. 2014. Native silver resources in Iberia. En Metals of Power - Early gold and silver. 6th Archaeological Conference of Central Germany. pp. 257-267, Halle (Saale).

Nielsen, A. 2007. Bajo el hechizo de los emblemas: políticas corporativas y trafico interregional en los Andes circumpuneños. En Producción y circulación prehispánicas de bienes en el sur andino, A. Nielsen, M. C. Rivolta, V. Seldes, M. M. Vázquez \& P. Mercolli, Eds., pp. 393-412. Córdoba: Brujas.

Niemeyer, H., Cervellino, M. \& Castillo, G. 1989. Los primeros ceramistas del Norte Chico: complejo El Molle (0 a 800 DC). En Prehistoria, desde sus orígenes hasta los albores de la conquista, J. Hidalgo, V. Schiappacasse, H. Niemeyer, C. Aldunate \& I. Solimano, Eds., pp. 227-263. Santiago: Andrés Bello. 
Niemeyer, H., Cervellino, M. \& Castillo, G. 1991. Los Períodos Temprano y Medio en la cuenca del río Pulido, Provincia de Copiapó, III Región de Atacama. Actas del XI Congreso Nacional de Arqueología Chilena (Santiago 1988) Tomo III: 1-30. Santiago.

Niemeyer, H., Cervellino, M. \& Castillo, G. 1998. Culturas prehistóricas de Copiapó. Copiapó: Museo Regional de Atacama.

PlazA, M. 2010. Estudio sobre la metalurgia incaica en Chile Central durante el Período Alfarero Tardío. Memoria para optar al título de Arqueóloga, Departamento de Antropología, Universidad de Chile, Santiago.

Rodríguez, J. \& GoRetTi, M. 2006. Tesoros precolombinos del Noroeste Argentino. Buenos Aires: Fundación CEPPA, Museo de Arte Hispanoamericano Isaac Fernández Blanco.

Soто, C. 2015. Amuletos en el cuerpo, ofrendas a las huacas: reflexiones sobre cultura material y visual desde los objetos perforados y sus usos en el Período Formativo (1500 AC800 DC) del desierto de Atacama (II Región, Chile). Tesis para optar al grado de Magister en Artes, mención Teoría e Historia del Arte, Departamento de Teoría e Historia del Arte, Universidad de Chile.

Troncoso, A. 2012. Arte rupestre y camélidos en el norte semiárido de Chile: una visión desde el Choapa. Boletín del Museo Chileno de Arte Precolombino 17 (1): 75-93. Santiago.

Troncoso, A., Larach, P., Alfaro, S., Pascual, D. \& Pavlovic, D. 2012. Nuevos antecedentes para el Período Alfarero temprano en la cuenca del Choapa: el sitio Los Mellizos (cuenca superior del río Illapel). Actas del XviII Congreso Nacional de Arqueología Chilena: 309-319. Santiago.
Troncoso, A. \& Pavlovic, D. 2013. Historia, saberes y prácticas: un ensayo sobre el desarrollo de las comunidades alfareras del norte semiárido chileno. Revista Chilena de Antropología 27: 101-140. Santiago.

Troncoso, A., Vergara, F., Pavlovic, D., González, P., Pino, M., Larach, P., Escudero, A., La Mura N., Moya, F., Pérez, I., Gutiérrez, R., Pascual, D., Belmar, C., Basile, M., López, P., DÁvila, C., VÁsquez, M. \& Urzúa, P. 2016 a. Dinámica espacial y temporal de las ocupaciones prehispánicas en la cuenca hidrográfica del río Limarí $\left(30^{\circ}\right.$ lat. S). Chungara 48 (2): 199-224. Arica.

Troncoso, A., Cantarutti, G. \& González, P. 2016 b. Desarrollo histórico y variabilidad espacial de las comunidades alfareras del norte semiárido (ca. 300 años AC a 1450 años DC). En Prehistoria de Chile, desde sus primeros habitantes hasta los Incas, F. Falabella, M. Uribe, L. Sanhueza, C. Aldunate \& J. Hidalgo Eds., pp. 319-364. Santiago: Universitaria-Sociedad Chilena de Arqueología. ZABURLín, M. 2016. Vasijas zoomorfas prehispánicas de la puna de Jujuy (Argentina): una propuesta de análisis semiótico. Boletín del Museo Chileno de Arte Precolombino 21 (2): 137-152. Santiago. 